Center for

Mathematical Economics

Working Papers

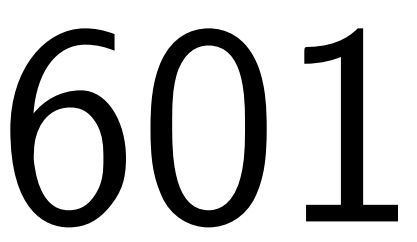

August 2018

Social Networks, Promotions, and the Glass-Ceiling Effect

Michael Neugart and Anna Zaharieva

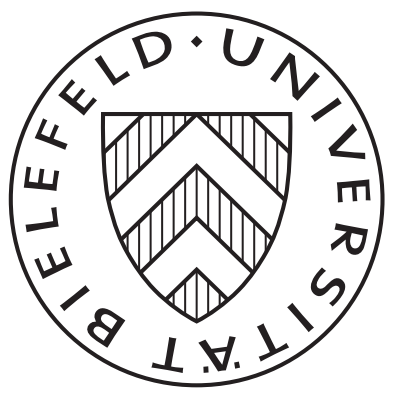

Center for Mathematical Economics (IMW) 


\title{
Social Networks, Promotions, and the Glass-Ceiling Effect
}

\author{
Michael Neugart*and Anna Zaharieva ${ }^{\dagger}$
}

August 31, 2018

\begin{abstract}
Empirical studies show that female workers are under-represented in highest hierarchical positions of companies, which is known as the glass-ceiling effect. In this study we investigate the relationship between social networks and the glass-ceiling effect. Specifically, we develop an equilibrium search and matching model where job ladders consist of three hierarchical levels and social networks are generated endogenously. Male and female workers move up in the hierarchical ladder via job-to-job transitions between firms and internal promotions within firms. They also accumulate experience which is a necessary requirement for applying to jobs in the highest hierarchical level. Open vacancies can be filled by formal matching of applicants to jobs or by referrals, which implies that senior workers recommend their social contacts for the job. Social networks exhibit gender homophily, which reflects the fact that social ties are more likely to be formed between workers of the same gender. In a setting when female workers are the minority, there are too few female contacts in the social networks of their male colleagues. This disadvantage implies that female workers are refereed less often for the jobs and under-represented in senior hierarchical positions of firms. We show that referrals via homophilous social networks can explain part of the total wage gap stemming from the glass-ceiling effect in Germany $(6.4 \%)$. This mechanism is amplified by more hierarchical firm structures, stronger clustering of social networks, and earlier promotion times.
\end{abstract}

Keywords: glass-ceiling effect, networks, discrimination, theory of the firm, promotions, search-and-matching labor market

JEL-classification: D21, D85, J31, J63, J71

${ }^{*}$ Technische Universität Darmstadt, Department of Law and Economics, Hochschulstrasse 1, D-64289 Darmstadt, Germany, e-mail: neugart@vwl.tu-darmstadt.de, phone: +49 6151 1657266, FAX: +49 61511657267

${ }^{\dagger}$ Bielefeld University, Faculty of Business Administration and Economics and Center for Mathematical Economics (IMW), Universitätsstrasse 25, 33615 Bielefeld, Germany, e-mail: azaharieva@wiwi.uni-bielefeld.de, phone: +49 521 106-5637, FAX: +49 521 106-89005 


\section{Introduction}

Women are much less represented on the managerial level of firms than men. This is known as the glass-ceiling effect. Moreover, women earn substantially less than men. ${ }^{1}$

In how far the under-representation of women in decision making positions contributes to the gender wage gap can be exemplified with the help of a Blinder-Oaxaca decomposition (Oaxaca, 1973) of the raw gender wage differentials for Germany. Table 1 shows the male and female employment shares and gross monthly wages by hierarchical level for a sample of 2403 highskill full-time employees drawn from the records of the German Socio-Economic Panel (SOEP). Females are less likely to occupy the top and middle management positions with only $13.9 \%$ of women in this group reaching the upper level and $64.3 \%$ remaining in non-management jobs. Moreover, positions in top and middle management pay on average $71 \%$ more than nonmanagement positions.

Table 1: Employment shares and wages

\begin{tabular}{l|c|c|c||c|c}
\hline & \multicolumn{3}{|c||}{ Fractions in \% } & \multicolumn{2}{c}{ Predicted wages, all } \\
Hierarchical level & Females & Males & All & in $€$ & Normalized \\
\hline Middle/top management jobs & 13.94 & 25.78 & 21.09 & 5579.0 & 1.713 \\
Lower management jobs & 21.76 & 27.32 & 25.12 & 4295.0 & 1.319 \\
Non-management jobs & 64.30 & 46.90 & 53.79 & 3255.4 & 1.000 \\
\hline
\end{tabular}

Data source: SOEP (2013).

The same data shows that the gender wage gap in this group of full-time high skilled men and women amounts to $31 \%$. Out of this difference $16.4 \%$ is the endowment effect, i.e. the fraction of the wage difference that is related to women having different socio-economic characteristics or jobs. In particular, within the endowment effect $10 \%$ can be explained by the fact that females are younger, less experienced, overrepresented in service occupations, and employed in smaller firms. In addition, the female participation rate is higher in Eastern Germany and the average salary level is lower in this region which contributes significantly to the gender wage gap. We do not find significant differences in formal qualification and education indicating that conventional human capital explanation for the gender wage gap vanished in Germany as it did in other developed economies (see Blau and Kahn, 2017, for the US). The remaining 6.4\% of the endowment effect are explained by the fact that women are situated in lower hierarchical positions than men, which can be interpreted as the glass-ceiling effect. ${ }^{2}$ This evidence, once more, underpins the assessment by Francois (1998) that "In contemporary labor markets, discrimination rarely takes the form of women being paid less than men in the same jobs at the same establishments, but is manifest in men having better access to higher paying jobs within an occupation type, even when traditional labor market characteristics are controlled for." (p.4).

\footnotetext{
${ }^{1}$ According to McKinsey\&Company (2017), based on data of 222 U.S. companies employing more than 12 million people, women are significantly underrepresented in the corporate pipeline, and at every higher level the representation of women declines. Among the largest listed companies in the 28 countries of the European Union only $15.8 \%$ of the decision making positions were held by women in 2017, see Gender Statistics Database, Women and Men in Decision Making http://eige.europa.eu/gender-statistics/dgs/indicator/wmidm_bus_ bus__wmid_comp_compex/bar/table. Based on Eurostat's Structure of Earnings Survey, the International Labor Office reports, see ILO (2016, p.82), an overall gender pay gap close to 20\%. For Chief Executive Officers (CEOs) the gap is twice as large and it continues to wide to $50 \%$ among the top $1 \%$ earners.

${ }^{2}$ Further details of the Blinder-Oaxaca decomposition are presented in Appendix I.
} 
Our paper addresses the gender wage gap arising from females not making it to the higher managerial positions in firms. We develop a search and matching model with referral hiring via endogenous professional networks that accounts for job-to-job mobility and internal promotions within hierarchical firms. We use our model to shed light on gender inequality generated by differences in the endogenous formation of professional networks between men and women and evaluate the magnitude of this effect for realistic parameter values. In particular, we ask the following questions: (a) Can there be an unequal representation of women along the hierarchy of firms without discrimination and occupational segregation? (b) Is there a role to be played for the depth of firms' hierarchies with respect to gender representation? (c) What is the contribution of contact network characteristics to females' employment shares on managerial positions, and finally (d) What effect does gender-based discrimination in promotions have on females' representation in managerial jobs?

Our model follows the lines of Dawid et al. (2018) extended in three important dimensions. First, we consider two gender groups featuring lower participation rates of women in the market for professional full-time jobs. Second, we incorporate hierarchical firms for which we can change the depth of the hierarchy. So workers can obtain wage increases by means of internal promotions and by moving to new employers. In modeling internal promotions we follow the seminal approach by Gibbons and Waldman (1999), so workers need to accumulate a specific level of experience/human capital in order to be considered for a promotion. Third, we generate endogenous professional networks for both worker groups. We model network formation as a random process over time. ${ }^{3}$ Workers meet at random and establish new network links, while existing links are destroyed at some exogenous rate. An important feature of our model is that link formation is subject to gender homophily implying that similar workers are more likely to form social links (McPherson et al., 2001). Firms can promote workers internally or post vacancies on an external market to which workers from other firms can apply. There is network recruitment on the external market such that applicants may be referred by an internal member of the firm with whom they share a network link.

Several new results can be obtained from our framework. We find that an unequal representation of women along the hierarchy of firms, that is the glass-ceiling effect, can emerge without occupational segregation, direct discrimination in formal hiring, or unequal promotion chances. For this to occur in our set-up, women need to be under-represented in the labor market and network formation has to be homophilous. Intuitively, network homophily implies that individuals from the same gender group are more likely to communicate with each other and establish a network link. Later this network link may lead to a job referral which helps workers to progress in their careers by means of job-to-job transitions. The fact that referral hiring exhibits a gender bias is empirically documented by Fernandez and Sosa (2005). We show that gender-biased referring does not lead to wage inequality if the two gender groups are equally large. It is only if women are a minority in their occupation, lower probability of creating social links with the majority group of men generates smaller professional networks of women, and leads to the disadvantage in the career progression as long as referral hiring is at place. The effect of homophilous networks on the glass-ceiling effect is amplified for deeper firm hierarchies, shorter promotion times, and more clustered networks as they arise with triadic closures in the

\footnotetext{
${ }^{3}$ For strategic network formation in the labour market see an early study by Calvó-Armengol (2004).
} 
spirit of Simmel (1908). Numerically, we find that network homophily combined with a minority status of women (30\% of the labour force in the occupation) may explain up to $42 \%$ of the wage gap attributed to the glass-ceiling effect. This means up to $2.7 \%$ out of $6.4 \%$ in a country like Germany. Finally, we find that the gender-wage differential increases even further as we allow for discrimination along the promotion path in firms.

We proceed with a review of the related literature. In Section 3 we introduce our analytical apparatus, and in Section 4 we present the results with respect to the network formation and the gender distribution along the hierarchical levels of the firm. In Section 5 we introduce extensions to our analytical framework and analyze them within an agent-based simulation. The last section concludes.

\section{Literature review}

We are not aware of formal investigations of how networks, referrals, and the depth of firm hierarchies are associated with each other in search and matching labor markets. Each of these topics has received considerable attention on its own, however. Since M. Granovetter's assertion that "Careers are not made up of random jumps from one job to another, but rather that individuals rely on contacts acquired at various stages of their work-life, and before. (1995, p.85)" various empirical studies confirmed that a large fraction - sometimes close to and above $50 \%$ - of the employees found their jobs via personal contacts. ${ }^{4}$

From a theoretical perspective the seminal model on referral hiring was developed by Montgomery (1991) who formalized the idea of network homophily. In particular, he described homophily by ability, when high ability employees recommend high ability contacts from their network. This approach was incorporated into a search and matching model by Galenianos (2013), however, none of the two studies considers gender homophily and hierarchical firms. Other theoretical contributions on referral hiring in a search and matching framework include Calvó-Armengol and Zenou (2005), Ioannides and Soetevent (2006), Fontaine (2008), Galenianos (2014) and Stupnytska and Zaharieva (2017). Galenianos (2014) investigates cross-sectional frequency of referrals and shows that more intensive referral hiring is associated with more efficient matching in a given sector. Ioannides and Soetevent (2006) and Fontaine (2008) show that larger social networks improve job-finding chances of unemployed workers as well as their wage bargaining position in the negotiation with firms. This mechanism implies that heterogeneity in the composition of networks is translated into the equilibrium wage inequality. Hence, their focus is on network-driven differences in wages earned by workers performing identical jobs. In contrast to this approach, we assume that wages in the same jobs are identical for all workers and investigate the role of social networks for the distribution of workers across different hierarchical positions. The particular mechanism of referral hiring that we use is similar to Calvó-Armengol and Zenou (2005) and Stupnytska and Zaharieva (2017).

To the best of our knowledge there are only three studies that analyze the implications of social networks in the market with job-to-job mobility. These are Horvath (2014), Zaharieva (2015) and Arbex et al. (2018). The latter paper builds on the early work by Mortensen and

\footnotetext{
${ }^{4}$ Pistaferri (1999) shows it for Italy, Addison and Portugal (2002) for Portugal, Bentolila et al. (2010) and Pellizzari (2010) for the United States and the European Union, and Rebien et al. (2017) for Germany.
} 
Vishwanath (1994) and assumes that employees refer their friends to jobs with the same wage as their own. In this case the distribution of network offers is superior to the standard wage offer distribution. A different approach is undertaken in Horvath (2014) and Zaharieva (2015). In these studies employees forward job offers that are (weakly) worse then their own, so network job offers are negatively selected. This selection effect is also present in our model since workers refer their network contacts to lower hierarchical positions than their own, but there is an additional competition effect: if one worker group moves faster in the job ladder it reduces the number of senior positions available to the other group, because the two groups are directly competing for a fixed number of jobs. This effect is absent in the previous work.

Next our study is related to the literature analysing job search via social networks in a simulation framework. This group of studies includes Calvó-Armengol and Jackson (2004), Bramoullé and Saint-Paul (2010), or König et al. (2014), as well as work that has taken the agent-based simulation approach as, among others, Tassier and Menczer (2008), Gemkow and Neugart (2011), or Dawid and Gemkow (2013). None of these contributions, however, modeled the hiring and promotion decisions of firms with hierarchies in connection with endogenously evolving social networks.

Following the "Invisibility Hypothesis" by Milgrom and Oster (1987) several studies mention the fact that women have a lack of "old-boys-club" connections as another factor for worse positioning of women in the job ladders (Cassidy et al., 2016; Bertrand et al., 2018). Even though differences in professional networks between men and women are often mentioned as a factor for observed diverging labor market performances, so far there were hardly any attempts to investigate the underlying mechanism with notable exceptions by Rubineau and Fernandez (2013, 2015). They analyze the interaction of the supply and demand side for hiring decisions of firms theoretically with Markov switching models. Contrary to their analyses, we place hierarchical firms in a labor market with search frictions. Empirically, the demand side perspective was investigated by Kmec (2005) who look into the organizational practices to locate and hire workers, or by Fernandez and Abraham (2010, 2011), Fernandez and Campero (2017) and Fernandez-Mateo and Fernandez (2016) who show that the gendered composition across levels of the organization can be traced back to the gendered nature of the candidate pools for jobs at the different levels.

Given that referral hiring is an important feature of the labour market and social networking becomes more relevant with a rapid development of communication software (e.g. Facebook, LinkedIn) our study attempts to investigate the role of social and professional networks for gender inequality in the presence of hierarchical firms. Our contribution seeks to offer a theoretical model that clarifies the mechanisms that may underlie these empirical findings. In a setting with hierarchical firms initial segregation of homophilous referral networks leads to a smaller fraction of women reaching senior positions. This implies that women have lower chances of recommending new applicants to mid-level positions contrary to Rubineau and Fernandez (2015). So demand-side effects are endogenous and amplify the segregating effect of homophilous network recruitment in our model.

Related to the hierarchical nature of the firms, one may also mention studies that document gender-based discrimination in the process of formal hiring, see Firth (1982) for the UK, Neumark et al. (1996) for the US, and Petit (2007) for France, or along the promotion path of firms. Blau and DeVaro (2007), Kauhanen and Napari (2015) and Cassidy et al. (2016) show that women 
have lower promotion probabilities within firms in the US and in Finnland. However, unequal promotion chances are not supported for countries like Germany and the United Kingdom, see Chadi and Goerke (2018) and Booth et al. (2018), respectively. We take up the issue of discrimination along the promotion path of firms in one of our simulation-based extensions.

Finally, the search and matching framework introduced by Diamond (1982), Mortensen (1982), and Pissarides (1985) within which we model firms' recruitment behavior and workers' network formation has become one of the workhorse models in labor economics.

\section{The Model}

In a nutshell our model has the following characteristics: time is continuous and workers enter and exit the market at an exogenous rate $\rho$. The total population size is normalized to 1 and there is no population growth. There are two types of agents: female workers $(F)$ and male workers $(M)$. Fraction $h \leq 0.5$ of workers are of type $F$ and fraction $1-h \geq 0.5$ are of type $M$. This parameter allows us to capture the lower participation rate of women in professional full-time jobs. All workers are identical with respect to their education. Job ladders consist of three hierarchical levels: low-level jobs, middle management and senior management. Later in the paper we also consider an extension to four levels. Positions in the first hierarchical level are freely available to all workers without search frictions. Further, there are two separate submarkets with search frictions: in the first submarket young workers apply for positions in middle management. In these positions workers accumulate experience on the job and as they have reached a sufficient level $(\bar{x})$ they qualify for a senior managerial job. They are promoted by their current employer if there is a vacancy on the senior level in their firm, otherwise they start applying for senior positions in the second submarket. For external hires, workers who get a referral have a competitive edge. They may get a referral from a worker on a higher hierarchical level of the hiring firm who is a member of their network. These networks form endogenously and can be homophilous.

In Section 3.1 we describe how social networks are formed and continue with the referral process via networks in Section 3.2. Further, in Section 3.3 we describe the structure of firms and workers' mobility patterns within and between firms.

\subsection{Social networks}

At rate $\phi$ every worker can be randomly matched with another worker. Formation of social links is subject to (gender) homophily, that is workers are more likely to create social links with others of the same type (see McPherson et al., 2001). Let $\tau_{0}$ denote the probability of creating a social link with a worker of a different type and $\tau \geq \tau_{0}$ be the probability of creating a link with another worker of the same type (conditional on matching). Note that the special case when $\tau=\tau_{0}$ corresponds to the situation without homophily. We consider directed links. This means that, if two workers $A$ and $B$ are randomly matched, it is possible that $B$ becomes a social contact of $A$ but not vice versa. The reason behind this assumption is that we only keep track of professional contacts rather than friendship ties, and assume that the person is ready to give a job referral/recommendation to each of his/her contacts at any point in time. Thus, our setting captures situations where person $A$ is ready to refer person $B$ for the job but not necessarily 
the other way round. Intuitively, this is similar to the directed links in citation networks. Every social link can be destroyed at rate $\delta$.

Let $\xi_{k}^{i j}$ denote a fraction of type $i$ workers with exactly $k$ social contacts of type $j, i, j \in$ $\{M, F\}$. This is a fraction out of all type $i$ workers. Consider some type $M$ worker without contacts of the same type. With our notation this worker belongs to the group $\xi_{0}^{M M}$. At rate $\phi$ this worker is matched with some other agent. With probability $1-h$ this agent is of the same type $M$, and the social link is created with probability $\tau$. Next consider a worker of type $M$ with only one contact of the same type belonging to the group $\xi_{1}^{M M}$. This person may lose his contact at rate $\delta$. In the steady state (when variables $\xi_{k}^{M M}$ are constant), the propensity for the worker to make transition between the two states $k-1$ and $k$ will be equalized, this means:

$$
\begin{array}{ll}
\xi_{0}^{M M} \phi(1-h) \tau=\delta \xi_{1}^{M M} & \Rightarrow \xi_{1}^{M M}=\frac{\xi_{0}^{M M} \phi(1-h) \tau}{\delta} \\
\xi_{1}^{M M} \phi(1-h) \tau=2 \delta \xi_{2}^{M M} & \Rightarrow \quad \xi_{2}^{M M}=\xi_{0}^{M M}\left(\frac{\phi(1-h) \tau}{\delta}\right)^{2} \frac{1}{2} \\
\xi_{k-1}^{M M} \phi(1-h) \tau & =k \delta \xi_{k}^{M M} \quad \Rightarrow \quad \xi_{k}^{M M}=\xi_{0}^{M M}\left(\frac{\phi(1-h) \tau}{\delta}\right)^{k} \frac{1}{k !}
\end{array}
$$

Let $\psi_{M M} \equiv \phi(1-h) \tau / \delta$. Since all fractions $\xi_{k}^{M M}$ should add up to 1 for $k=0 \ldots \infty$ we get: $\xi_{0}^{M M}=e^{-\psi_{M M}}$ and the number of type $M$ contacts has a Poisson distribution with parameter $\psi_{M M}$. Intuitively, $\psi_{M M}$ is the average number of male contacts in the professsional network of a randomly chosen male worker:

$$
\xi_{k}^{M M}=e^{-\psi_{M M}}\left(\psi_{M M}\right)^{k} \frac{1}{k !}
$$

Alternatively, the type $M$ person can be matched with another person of type $F$, which happens at rate $\phi h$. So the social link is formed at rate $\tau_{0}$. Repeating the same steps as above we get:

$$
\xi_{k}^{M F}=e^{-\psi_{M F}}\left(\psi_{M F}\right)^{k} \frac{1}{k !} \quad \text { where } \quad \psi_{M F} \equiv \frac{\phi h \tau_{0}}{\delta}
$$

Here $\psi_{M F}$ is the average number of female contacts in the professsional network of a randomly chosen male worker. Let $n_{M}$ denote the average network size for type $M$ workers and $\gamma_{M}$ be the fraction of type $M$ contacts in the network, so we get:

$$
n_{M}=\psi_{M M}+\psi_{M F}=\frac{\phi}{\delta}\left[(1-h) \tau+h \tau_{0}\right] \quad \gamma_{M}=\frac{(1-h) \tau}{(1-h) \tau+h \tau_{0}}
$$

Using the same approach for type $F$ workers we get:

$$
n_{F}=\psi_{F F}+\psi_{F M}=\frac{\phi}{\delta}\left[h \tau+(1-h) \tau_{0}\right] \quad \gamma_{F}=\frac{h \tau}{h \tau+(1-h) \tau_{0}}
$$

where $n_{F}$ is the total network size of female workers and $\gamma_{F}$ is a fraction of type $F$ contacts in their network. One can see that the case of full homophily $\left(\tau_{0}=0\right)$ leads to the complete segregation of social networks between the two genders, that is $\gamma_{M}=\gamma_{F}=1$. In the opposite case without homophily $\left(\tau_{0}=\tau\right)$, the fraction of contacts of the same type is equal to the fraction 
of this type in the total population, that is $\gamma_{M}=1-h$ and $\gamma_{F}=h$. Comparing the average sizes of social networks for male and female workers one can show the following:

$$
n_{M}-n_{F}=\frac{\phi}{\delta}\left[(1-h) \tau+h \tau_{0}-h \tau-(1-h) \tau_{0}\right]=\frac{\phi}{\delta}(1-2 h)\left(\tau-\tau_{0}\right)
$$

Thus male workers have larger networks on average $\left(n_{M}>n_{F}\right)$ for $h<0.5$ and $\tau_{0}<\tau$. Intuitively, this shows that professional networks of women tend to be smaller compared to men if women are the minority in the labour market $(h<0.5)$ and social connections exhibit some degree of homophily $\left(\tau_{0}<\tau\right)$. We can also see that female contacts are underrepresented in the networks of male workers $\left(1-\gamma_{M}<h\right)$, whereas they are overrepresented in the networks of female workers $\left(\gamma_{F}>h\right)$ :

$$
\begin{aligned}
1-\gamma_{M} & =\frac{h \tau_{0}}{(1-h) \tau+h \tau_{0}}=h \frac{1}{(1-h) \frac{\tau}{\tau_{0}}+h}<h \quad \text { for } \quad \tau_{0}<\tau \\
\gamma_{F} & =\frac{h \tau}{h \tau+(1-h) \tau_{0}}=h \frac{1}{(1-h) \frac{\tau_{0}}{\tau}+h}>h \quad \text { for } \quad \tau_{0}<\tau
\end{aligned}
$$

Recall that $h$ is the fraction of women participating in the labour market. This finding forms the ground for gender-biased referrals in our model which is presented in the following section.

\subsection{Labour market}

There are three types of jobs in the market: low-level, mid-level and high-level jobs. For simplicity we assume that there are no frictions in the market for low-level jobs and there are infinitely many of these jobs available to both worker groups. For the purpose of tractability we assume that there is no unemployment in the model, however, low-level jobs are intuitively similar to the state of unemployment, hence all workers in low-level jobs are searching and applying for better positions. Firms providing low-level jobs are not explicitly modeled in the paper. Let $e_{0}^{i}$ denote the measure/number of type $i$ workers employed in low-level jobs, $i=M, F$. Workers do not gain any professional experience by performing low-level jobs.

In addition to firms offering low-level jobs there are professional positions provided by firms operating in a frictional market. The total number of these firms is fixed and denoted by $d$. All these firms are identical and every firm is a dyad consisting of two positions: one middle level position (supervisor) and one senior level position (manager). Thus job ladders consist of three hierarchical levels. Here we build on the model by Dawid et al. (2018). In Section 5 we extend our benchmark model to more than three levels and analyse the implications of deeper firm hierarchies. At rate $\rho$ every worker may exit the market for exogenous reasons and is substituted with a new agent of the same gender who enters the pool of young inexperienced workers $e_{0}=e_{0}^{M}+e_{0}^{F}$. So the total population is constant over time. From the perspective of firms $\rho$ is the job destruction shock. Let $e_{1}^{i}$ denote the number of type $i$ workers employed in mid-level jobs and $e_{2}^{i}$ - the number of type $i$ workers employed in senior jobs, $i=M, F$, so:

$$
e_{0}^{F}+e_{1}^{F}+e_{2}^{F}=h \quad \text { and } \quad e_{0}^{M}+e_{1}^{M}+e_{2}^{M}=1-h
$$

Once accepted in the mid-level position workers start accumulating professional experience $x \geq 0$ 
with $\dot{x}=1$. All workers in mid-level jobs have to accumulate an exogenously given experience level $\bar{x}$ to become eligible for senior positions. Here we follow the human capital approach to promotions developed by Gibbons and Waldman (1999). Experience accumulation is costly for workers so it stops at $\bar{x}$ since there are no incentives for workers to accumulate more human capital than required by firms. This is also a proxy for the decreasing returns to learning-bydoing. If the senior position is open, firms commit to promote their employees with experience $\bar{x}$ to senior positions. If there is no worker eligible for promotion the firm is posting an open high-level vacancy on the external market. If there is no open senior position in the firm, the worker with experince $\bar{x}$ starts applying to senior positions in other firms. This is the process of on-the-job search. Experience $x$ is observable and can be transferred to other firms if the worker changes the job voluntarily. Workers with experience $x<\bar{x}$ are not eligible for senior positions in any company, thus there are no reasons for them to search on-the-job. Note that the experience requirement $\bar{x}$ and the probability of internal promotion are identical for male and female workers. We make this assumption as the evidence on promotion chances for men and women within firms is inconclusive. This assumption also allows us to focus on the role of social networks and investigate this channel in the isolation from other factors generating the glass-ceiling effect. We extend our benchmark framework and consider unequal promotion chances and their interaction with the network channel in Section 5.

There are two separate matching markets in our model, one where firms post mid-level positions and anticipate inexperienced workers with $x=0$ and another one where firms post their senior positions and anticipate workers with experience $x=\bar{x}$. Variable $d_{00}$ denotes the stock of empty firms in the market, whereas $d_{01}$ is the stock of firms with a senior manager but no supervisor. Since all these firms have an open mid-level position the total stock of open mid-level positions available for matching is equal to $d_{00}+d_{01}$. These positions are randomly matched with $z_{1} e_{0}$ searching workers employed in low-level jobs, where $z_{1}$ denotes exogenous search effort of workers applying to mid-level jobs. More precisely, $z_{1}$ is the fraction of searching workers who prepare and send an application at every instant of time. To determine the number of matches in the submarket for mid-level positions we use an urn-ball matching mechanism (see, e.g., Petrongolo and Pissarides, 2001). This mechanism yields the formal matching rate $q_{1}$ for firms:

$$
q_{1}=1-\left(1-\frac{1}{d_{00}+d_{01}}\right)^{z_{1} e_{0}}
$$

With probability $\alpha_{1}=e_{0}^{M} / e_{0}$ the chosen candidate is of type $M$ and with a counterprobability $\left(1-\alpha_{1}\right)=e_{0}^{F} / e_{0}$ the person is of type $F$. Note that:

$$
\alpha_{1}=\frac{(1-h) \mu_{M}}{(1-h) \mu_{M}+h \mu_{F}}
$$

where $\mu^{i}=e_{0}^{i} /(1-h)$ is the equilibrium fraction of type $i$ workers employed in low-level jobs, $i=M, F$. This equation shows the following. If the distribution of workers across the hierarchical levels is identical for male and female workers, then $\mu_{M}=\mu_{F}$ and $\alpha_{1}=1-h$. So the probability that the hired job candidate is of type $M$ is equal to the population average $1-h$. However, if female workers are overrepresented at the bottom $\left(\mu_{F}>\mu_{M}\right)$ a randomly matched job candidate 
is more likely to be a female and $\alpha_{1}<1-h$.

In addition to the formal application process some mid-level positions can be filled by referrals. Consider firms of type $d_{01}$ consisting of $d_{0 F}$ and $d_{0 M}$, depending on the type of the senior manager. With probability $s$ in both types of firms the senior manager is asked to recommend a contact for the open mid-level position. On average, type $M$ managers have $n_{M} \gamma_{M}$ type $M$ contacts. So with probability $\left(1-\mu^{M}\right)^{n_{M} \gamma_{M}}$ the senior manager doesn't know any type $M$ candidate for the mid-level position. In addition, type $M$ managers have $n_{M}\left(1-\gamma_{M}\right)$ type $F$ social contacts, but with probability $\left(1-\mu^{F}\right)^{n_{M}\left(1-\gamma_{M}\right)}$ all of them are already employed in professional jobs. With this information we obtain the following probability that there is at least one social contact recommended by the male senior manager:

$$
\tilde{q}_{1}^{M}=s\left(1-\left(1-\mu_{M}\right)^{n_{M} \gamma_{M}}\left(1-\mu_{F}\right)^{n_{M}\left(1-\gamma_{M}\right)}\right)
$$

If the manager has several social contacts employed in low-level jobs, the manager randomly chooses one of them independent of the gender and refers this contact for the open position in his firm. The referred candidate is of type $M$ with probability $\tilde{\alpha}_{1}^{M}$ and of type $F$ with probability $1-\alpha_{1}^{M}$, where $\tilde{\alpha}_{1}^{M}$ depends on the composition of the network:

$$
\tilde{\alpha}_{1}^{M}=\frac{\gamma_{M} \mu_{M}}{\gamma_{M} \mu_{M}+\left(1-\gamma_{M}\right) \mu_{F}}=\frac{(1-h) \mu_{M}}{(1-h) \mu_{M}+h \mu_{F} \cdot \frac{\left(1-\gamma_{M}\right)(1-h)}{\gamma_{M} h}}
$$

This equation shows that $\tilde{\alpha}_{1}^{M}>\alpha_{1}$ in homophilous networks because $\frac{\left(1-\gamma_{M}\right)(1-h)}{\gamma_{M} h}<1$ for $\tau_{0}<\tau$. Intutively, this means that a candidate referred by the male manager is more likely to be a male worker compared to the formal channel even if the manager doesn't have any taste for discrimination and randomizes between all of his social contacts interested in the mid-level job. Following the same logic we define $\tilde{q}_{1}^{F}$ - the probability that there is at least one social contact recommended by the female senior manager:

$$
\tilde{q}_{1}^{F}=s\left(1-\left(1-\mu_{M}\right)^{n_{F}\left(1-\gamma_{F}\right)}\left(1-\mu_{F}\right)^{n_{F} \gamma_{F}}\right)
$$

Further, $\tilde{\alpha}_{1}^{F}$ - probability for a type $F$ manager of recommending a type $M$ candidate from the network, so that:

$$
\tilde{\alpha}_{1}^{F}=\frac{\left(1-\gamma_{F}\right) \mu_{M}}{\left(1-\gamma_{F}\right) \mu_{M}+\gamma_{F} \mu_{F}}=\frac{(1-h) \mu_{M}}{(1-h) \mu_{M}+h \mu_{F} \cdot \frac{\gamma_{F}(1-h)}{\left(1-\gamma_{F}\right) h}}
$$

This shows that a candidate recommended by the female manager is less likely to be a male worker compared to the formal hiring channel, that is $\tilde{\alpha}_{1}^{F}<\alpha_{1}$ for $\tau_{0}<\tau$.

Summarizing, we can see that firms with an open mid-level position and a type $M$ senior manager will fill their position with a type $M$ candidate at rate $q_{1} \alpha_{1}$ via the formal application process and via the network at rate $\tilde{q}_{1}^{M} \tilde{\alpha}_{1}^{M}$. We do not assume that the recommended candidate is preferred to the external candidates. Rather all applicants for a given mid-level position are pooled together and a random draw is made. So the recommended applicant has the same chances as external applicants given that all of them have the same qualification. Assuming preference for the recommended candidate would amplify the network effect in the quantitative 
estimation. Let the total job-filling rate with a type $M$ candidate be denoted by $\bar{q}_{1}^{M M}$. In addition, the open position can be filled with a type $F$ candidate at the total rate $\bar{q}_{1}^{F M}$ :

$$
\bar{q}_{1}^{M M}=q_{1} \alpha_{1}+\tilde{q}_{1}^{M} \tilde{\alpha}_{1}^{M} \quad \text { and } \quad \bar{q}_{1}^{F M}=q_{1}\left(1-\alpha_{1}\right)+\tilde{q}_{1}^{M}\left(1-\tilde{\alpha}_{1}^{M}\right)
$$

Finally, consider firms with an open mid-level position and a type $F$ senior manager. These firms will fill their position with a type $M$ candidate at rate $q_{1} \alpha_{1}$ via the formal application process and via the network at rate $\tilde{q}_{1}^{F} \tilde{\alpha}_{1}^{F}$. Let the total job-filling rate with a type $M$ candidate be denoted by $\bar{q}_{1}^{M F}$. In addition, the open position can be filled with a type $F$ candidate at the total rate $\bar{q}_{1}^{F F}$ :

$$
\bar{q}_{1}^{M F}=q_{1} \alpha_{1}+\tilde{q}_{1}^{F} \tilde{\alpha}_{1}^{F} \quad \text { and } \quad \bar{q}_{1}^{F F}=q_{1}\left(1-\alpha_{1}\right)+\tilde{q}_{1}^{F}\left(1-\tilde{\alpha}_{1}^{F}\right)
$$

Notice the following, when referral hiring is not used, that is $s=0$, the rate at which a male candidate is hired is equal to $q_{1} \alpha_{1}$, and the rate at which a female candidate is hired is equal to $q_{1}\left(1-\alpha_{1}\right)$. Both are independent of the gender of the senior manager.

Further, let $d_{10}=d_{F 0}+d_{M 0}$ denote firms with a middle-level worker but no senior manager. This means that the total number of open managerial positions is given by $d_{00}+d_{10}$. Finally, let $d_{11}^{N}=d_{M F}^{N}+d_{M M}^{N}+d_{F F}^{N}+d_{F M}^{N}$ denote the stock of full firms with both employees, where the worker in the mid-level position is not yet eligible for promotion $(x<\bar{x})$. In a similar way, $d_{11}^{S}=d_{M F}^{S}+d_{M M}^{S}+d_{F F}^{S}+d_{F M}^{S}$ - is the stock of full firms, where the mid-level worker is already eligible for senior positions $(x=\bar{x})$ and searching on-the-job. This means that the stock of applicants in the managerial market is given by $z_{2} d_{11}^{S}$, where $z_{2}$ is the exogenous search intensity of experienced workers. So the urn-ball matching rate in the managerial market $q_{2}$ is given by:

$$
q_{2}=1-\left(1-\frac{1}{d_{00}+d_{10}}\right)^{z_{2} d_{11}^{S}}
$$

With probability $\alpha_{2}$ the firm will be matched with a type $M$ experienced mid-level worker and hire him for the manager position and with a counter-probability $1-\alpha_{2}$ the firm will be matched with a type $F$ experienced mid-level worker and hire her as a manager:

$$
\alpha_{2}=\frac{d_{M F}^{S}+d_{M M}^{S}}{d_{11}^{S}}
$$

So the total job-filling rate with a type $M$ candidate is given by $q_{2} \alpha_{2}$ and $q_{2}\left(1-\alpha_{2}\right)$ with a type $F$ candidate. Note that we assume that workers don't recommend their contacts for senior positions, so there are no referrals on this level. Also in our setting it is not rational for midlevel workers to refer their contacts for senior positions, since they are hoping to be promoted themselves in the future. Moreover, there is no favoritism and gender-based discrimination in the process of formal hiring as we seek to identify a separate effect of homophilous networks on labour market outcomes in isolation from other factors. 


\subsection{Firm Dynamics}

In this section we analyse the transformation of firms as workers enter and exit jobs as well as the steady-state distributions of workers and firms. Consider changes in the stock of empty firms $d_{00}$. Since every empty firm posts both the mid-level and the senior position in the respective submarkets it exits the state $d_{00}$ whenever it finds the first employee. So the outflow of firms from $d_{00}$ takes place at rate $q_{1}+q_{2}$. The inflow into this state consists of all firms with only one employee experiencing the job destruction/exit shock $\rho$. These are the firms $d_{F 0} d_{M 0}, d_{0 F}$ and $d_{0 M}$. In this paper we restrict our analysis to the steady states and consider a stationary distribution of workers and firms across states. This means that $\dot{d}_{00}=0$ in the steady state:

$$
0=\dot{d}_{00}=\rho\left(d_{F 0}+d_{M 0}+d_{0 F}+d_{0 M}\right)-\left(q_{1}+q_{2}\right) d_{00}
$$

Further, consider changes in the stocks of firms $d_{F 0}(x), d_{F M}^{N}(x)$ and $d_{F F}^{N}(x)$. Note that workers with experience $0 \leq x \leq \bar{x}$ are not yet searching on-the-job since their experience is not sufficient for managerial positions and there are no gains from changing to another mid-level job. This means that the inflow of firms into state $d_{F 0}(x)$ is equal to $\rho\left(d_{F M}^{N}(x)+d_{F F}^{N}(x)\right)$. These are the firms where the manager exits at rate $\rho$ and they are left with only one mid-level worker of type $F$. If the manager exits firms post the open position in the second submarket for experienced workers and find a manager at rate $q_{2}$. This means that the outflow of workers from the state $d_{F 0}(x)$ is equal to $\left(q_{2}+\rho\right) d_{F 0}(x)$ where the term $\rho d_{F 0}(x)$ corresponds to the job destruction shock $\rho$ of the mid-level position. So we get the following differential equation ${ }^{5}$ :

$$
\frac{\partial d_{F 0}(x)}{\partial x}=\rho\left(d_{F M}^{N}(x)+d_{F F}^{N}(x)\right)-\left(\rho+q_{2}\right) d_{F 0}(x)
$$

Next we take into account changes in the stock of firms $d_{F M}^{N}(x)$ and $d_{F F}^{N}(x)$. Each of these firms has exactly two filled positions, so the job destruction shock arrives at the increased rate $2 \rho$. The inflow of firms into category $d_{F F}^{N}(x)$ is equal to $q_{2}\left(1-\alpha_{2}\right) d_{F 0}(x)$. These are the firms $d_{F 0}(x)$ filling their senior position with a type $F$ candidate. In a similar way, the inflow of firms into category $d_{F M}^{N}(x)$ is equal to $q_{2} \alpha_{2} d_{F 0}(x)$. These are the firms $d_{F 0}(x)$ filling their senior position with a type $M$ candidate. So we get the following two differential equations:

$$
\begin{aligned}
\partial d_{F F}^{N}(x) / \partial x & =q_{2}\left(1-\alpha_{2}\right) d_{F 0}(x)-2 \rho d_{F F}^{N}(x) \\
\partial d_{F M}^{N}(x) / \partial x & =q_{2} \alpha_{2} d_{F 0}(x)-2 \rho d_{F M}^{N}(x)
\end{aligned}
$$

${ }^{5}$ In general the stock variable $d_{F 0}(x, t)$ may depend on time $t$, so the total derivative is given by:

$$
\frac{\partial d_{F 0}(x, t)}{\partial x} \frac{\partial x}{\partial t}+\frac{\partial d_{F 0}(x, t)}{\partial t}=\rho\left(d_{F M}^{N}(x)+d_{F F}^{N}(x)\right)-\left(\rho+q_{2}\right) d_{F 0}(x)
$$

Since the distribution of firms $d_{F 0}(x, t)$ is stationary in the steady state we set the time derivative $\dot{d}_{F 0}=\frac{\partial d_{F F}(x, t)}{\partial t}$ equal to zero. Moreover, experience $x$ is accumulating one to one with the time because $\dot{x}=\partial x / \partial t=1)$. 
The coefficient matrix of the three first order linear differential equations for $\left\{d_{F 0}(x), d_{F F}^{N}(x), d_{F M}^{N}(x)\right\}$ has three eigenvalues equal to: $-2 \rho,-\rho$ and $-\left(2 \rho+q_{2}\right)$. So the general solution is given by:

$$
\begin{aligned}
d_{F 0}(x) & =k_{2}^{F} \frac{\rho^{2}}{q_{2}} e^{-\rho x}-k_{3}^{F} q_{2} e^{-\left(2 \rho+q_{2}\right) x} \\
d_{F F}^{N}(x) & =k_{1}^{F} e^{-2 \rho x}+k_{2}^{F} \rho\left(1-\alpha_{2}\right) e^{-\rho x}+k_{3}^{F} q_{2}\left(1-\alpha_{2}\right) e^{-\left(2 \rho+q_{2}\right) x} \\
d_{F M}^{N}(x) & =-k_{1}^{F} e^{-2 \rho x}+k_{2}^{F} \rho \alpha_{2} e^{-\rho x}+k_{3}^{F} q_{2} \alpha_{2} e^{-\left(2 \rho+q_{2}\right) x}
\end{aligned}
$$

In order to find the constant terms $k_{1}^{F}, k_{2}^{F}$ and $k_{3}^{F}$ we use the following initial conditions: $q_{1}(1-$ $\left.\alpha_{1}\right) d_{00}=d_{F 0}(0), \bar{q}_{1}^{F F} d_{0 F}=d_{F F}^{N}(0)$ and $\bar{q}_{1}^{F M} d_{0 M}=d_{F M}^{N}(0)$. The first condition implies that the stock $d_{F 0}(0)$ consists of firms $d_{00}$ finding a mid-level worker of type $F$, that is $q_{1}\left(1-\alpha_{1}\right) d_{00}$. The second condition implies that the stock of firms $d_{F F}^{N}(0)$ consists of firms $d_{0 F}$ who find a mid-level worker of type $F$ at rate $\bar{q}_{1}^{F F}$. The third condition implies that the stock of firms $d_{F M}^{N}(0)$ consists of firms $d_{0 M}$ who find a mid-level worker of type $F$ at rate $\bar{q}_{1}^{F M}$. Exact expressions for $k_{1}^{F}, k_{2}^{F}$ and $k_{3}^{F}$ are provided in Appendix II.

Note that in all three states $d_{F 0}(x), d_{F F}^{N}(x), d_{F M}^{N}(x)$ female workers employed in midlevel positions remain inactive and accumulate experience till it reaches the minimum level $\bar{x}$ necessary for the senior position. If the senior position is free, the mid-level worker is immediately promoted, so the stock of firms $d_{F 0}(\bar{x})$ is one of the entries into the stock $d_{0 F}$. However, if the senior position is not vacant, then mid-level workers start searching and applying for senior positions in other firms. This means that stocks of firms $d_{F M}^{N}(\bar{x})$ and $d_{F F}^{N}(\bar{x})$ are the entries into $d_{F M}^{S}$ and $d_{F F}^{S}$ respectively. This meachanism allows us to obtain the total stocks of firms $d_{F 0}$, $d_{F F}^{N}$ and $d_{F M}^{N}$ be integrating from $x=0$ till $x=\bar{x}$. This yields the following:

$$
\begin{aligned}
d_{F 0} & =\frac{k_{2}^{F} \rho}{q_{2}}\left(1-e^{-\rho \bar{x}}\right)-\frac{k_{3}^{F} q_{2}}{2 \rho+q_{2}}\left(1-e^{-\left(2 \rho+q_{2}\right) \bar{x}}\right) \\
d_{F F}^{N} & =\frac{k_{1}^{F}}{2 \rho}\left(1-e^{-2 \rho \bar{x}}\right)+k_{2}^{F}\left(1-\alpha_{2}\right)\left(1-e^{-\rho \bar{x}}\right)+\frac{k_{3}^{F} q_{2}\left(1-\alpha_{2}\right)}{2 \rho+q_{2}}\left(1-e^{-\left(2 \rho+q_{2}\right) \bar{x}}\right) \\
d_{F M}^{N} & =-\frac{k_{1}^{F}}{2 \rho}\left(1-e^{-2 \rho \bar{x}}\right)+k_{2}^{F} \alpha_{2}\left(1-e^{-\rho \bar{x}}\right)+\frac{k_{3}^{F} q_{2} \alpha_{2}}{2 \rho+q_{2}}\left(1-e^{-\left(2 \rho+q_{2}\right) \bar{x}}\right)
\end{aligned}
$$

Next, we repeat our analysis with the stocks of firms $d_{M 0}(x), d_{M M}^{N}(x)$ and $d_{M F}^{N}(x)$, where there is a male worker employed in the mid-level position. This yields the following system of differential equations:

$$
\begin{aligned}
\partial d_{M 0}(x) / \partial x & =\rho\left(d_{M F}^{N}(x)+d_{M M}^{N}(x)\right)-\left(\rho+q_{2}\right) d_{M 0}(x) \\
\partial d_{M M}^{N}(x) / \partial x & =q_{2} \alpha_{2} d_{M 0}(x)-2 \rho d_{M M}^{N}(x) \\
\partial d_{M F}^{N}(x) / \partial x & =q_{2}\left(1-\alpha_{2}\right) d_{M 0}(x)-2 \rho d_{M F}^{N}(x)
\end{aligned}
$$

Firms of the type $d_{M 0}(x)$ are searching for a senior manager and find one at rate $q_{2}$. With probability $\alpha_{2}$ the chosen candidate is a male worker, so the firm makes transition into the state $d_{M M}^{N}(x)$. Here the mid-level employee is also a male worker with experience $x<\bar{x}$. With the counter-probability $1-\alpha_{2}$ the new senior manager is a female worker, so the firm makes a transition into the state $d_{M F}^{N}(x)$. The three eigenvalues of this system of differential equations 
are again $-2 \rho,-\rho$ and $-\left(2 \rho+q_{2}\right)$, so the general solution is:

$$
\begin{aligned}
d_{M 0}(x) & =k_{2}^{M} \frac{\rho^{2}}{q_{2}} e^{-\rho x}-k_{3}^{M} q_{2} e^{-\left(2 \rho+q_{2}\right) x} \\
d_{M M}^{N}(x) & =k_{1}^{M} e^{-2 \rho x}+k_{2}^{M} \rho \alpha_{2} e^{-\rho x}+k_{3}^{M} q_{2} \alpha_{2} e^{-\left(2 \rho+q_{2}\right) x} \\
d_{M F}^{N}(x) & =-k_{1}^{M} e^{-2 \rho x}+k_{2}^{M} \rho\left(1-\alpha_{2}\right) e^{-\rho x}+k_{3}^{M} q_{2}\left(1-\alpha_{2}\right) e^{-\left(2 \rho+q_{2}\right) x}
\end{aligned}
$$

In order to find the constant terms $k_{1}^{M}, k_{2}^{M}$ and $k_{3}^{M}$ we use the following initial conditions: $q_{1} \alpha_{1} d_{00}=d_{M 0}(0), \bar{q}_{1}^{M M} d_{0 M}=d_{M M}^{N}(0)$ and $\bar{q}_{1}^{M F} d_{0 F}=d_{M F}^{N}(0)$. The first condition implies that the stock $d_{F 0}(0)$ consists of firms $d_{00}$ finding a mid-level worker of type $M$, that is $q_{1} \alpha_{1} d_{00}$. The second condition implies that the stock of firms $d_{M M}^{N}(0)$ consists of firms $d_{0 M}$ who find a midlevel worker of type $M$ at rate $\bar{q}_{1}^{M M}$. The third condition implies that the stock of firms $d_{M F}^{N}(0)$ consists of firms $d_{0 F}$ who find a mid-level worker of type $M$ at rate $\bar{q}_{1}^{M F}$. Exact expressions for $k_{1}^{M}, k_{2}^{M}$ and $k_{3}^{M}$ are again provided in Appendix II. Finally, integrating variables $d_{M 0}(x)$, $d_{M M}^{N}(x)$ and $d_{M F}^{N}(x)$ from $x=0$ till $x=\bar{x}$ we get the following:

$$
\begin{aligned}
d_{M 0} & =\frac{k_{2}^{M} \rho}{q_{2}}\left(1-e^{-\rho \bar{x}}\right)-\frac{k_{3}^{M} q_{2}}{2 \rho+q_{2}}\left(1-e^{-\left(2 \rho+q_{2}\right) \bar{x}}\right) \\
d_{M M}^{N} & =\frac{k_{1}^{M}}{2 \rho}\left(1-e^{-2 \rho \bar{x}}\right)+k_{2}^{M} \alpha_{2}\left(1-e^{-\rho \bar{x}}\right)+\frac{k_{3}^{M} q_{2} \alpha_{2}}{2 \rho+q_{2}}\left(1-e^{-\left(2 \rho+q_{2}\right) \bar{x}}\right) \\
d_{M F}^{N} & =-\frac{k_{1}^{M}}{2 \rho}\left(1-e^{-2 \rho \bar{x}}\right)+k_{2}^{M}\left(1-\alpha_{2}\right)\left(1-e^{-\rho \bar{x}}\right)+\frac{k_{3}^{M} q_{2}\left(1-\alpha_{2}\right)}{2 \rho+q_{2}}\left(1-e^{-\left(2 \rho+q_{2}\right) \bar{x}}\right)
\end{aligned}
$$

To close the model, consider the stocks of firms $d_{F F}^{S}, d_{F M}^{S}, d_{M M}^{S}$ and $d_{M F}^{S}$. In all these firms the mid-level worker has experience more than $\bar{x}$ and is already searching for a senior position. We already know that $d_{F M}^{N}(\bar{x})$ and $d_{F F}^{N}(\bar{x})$ are the only entries into $d_{F M}^{S}$ and $d_{F F}^{S}$ respectively. In a similar way, variables $d_{M F}^{N}(\bar{x})$ and $d_{M M}^{N}(\bar{x})$ are the only entries into $d_{M F}^{S}$ and $d_{M M}^{S}$. There are three possible events that can alter the state of these firms. Either one of the two employees is dismissed from the job at rate $\rho$, or the mid-level worker finds another employment as a senior manager and quits the firm at rate $\lambda_{2}$. Thus we get:

$$
\begin{array}{llll}
\dot{d}_{F F}^{S}=d_{F F}^{N}(\bar{x})-\left(2 \rho+\lambda_{2}\right) d_{F F}^{S} & \dot{d}_{M M}^{S} & =d_{M M}^{N}(\bar{x})-\left(2 \rho+\lambda_{2}\right) d_{M M}^{S} \\
\dot{d}_{F M}^{S}=d_{F M}^{N}(\bar{x})-\left(2 \rho+\lambda_{2}\right) d_{F M}^{S} & \dot{d}_{M F}^{S} & =d_{M F}^{N}(\bar{x})-\left(2 \rho+\lambda_{2}\right) d_{M F}^{S}
\end{array}
$$

Finally, consider the stock of firms $d_{0 F}$. We already know that $d_{F 0}(\bar{x})$ is one of the entries into $d_{0 F}$, because mid-level workers are promoted to senior positions upon reaching experience $\bar{x}$. Also the firms $d_{F M}^{S}$ and $d_{F F}^{S}$ promote their female mid-level employees to senior positions in the event when the senior manager is dimissed, which happens at rate $\rho$. So the inflow of firms into $d_{0 F}$, which is due to immediate or delayed promotions is given by $d_{F 0}(\bar{x})+\rho\left(d_{F M}^{S}+d_{F F}^{S}\right)$.

However, also empty firms $d_{00}$ are searching for senior managers and find one at rate $q_{2}$. With probability $\alpha_{2}$ the new manager is a male worker, so the firm $d_{00}$ becomes $d_{0 M}$, but with probability $1-\alpha_{2}$ the new manager is a female worker, so the firm enters the state $d_{0 F}$. Hence the entry of firms into state $d_{0 F}$, which is due to outside hiring, is equal to $q_{2}\left(1-\alpha_{2}\right) d_{00}$.

In addition, we know that any of the firms $d_{F F}^{N}, d_{M F}^{N}, d_{F F}^{S}$ and $d_{M F}^{S}$ may lose their midlevel employees at rate $\rho$ due to the exogenous exit and therefore enter the state $d_{0 F}$ as the 
only remaining worker in these firms is a senior female manager. So the next entry is $\rho\left(d_{F F}^{N}+\right.$ $\left.d_{M F}^{N}+d_{F F}^{S}+d_{M F}^{S}\right)$. Moreover, it can also happen that mid-level employees in firms $d_{F F}^{S}$ and $d_{M F}^{S}$ separate from their employers due to quitting and taking employment in other firms, which happens at rate $\lambda_{2}$. This yields the last entry into the state $d_{0 F}$, namely, $\lambda_{2}\left(d_{F F}^{S}+d_{M F}^{S}\right)$. Summarizing, we find that the entry of firms into the state $d_{0 F}$ is given by $d_{F 0}(\bar{x})+\rho\left(d_{F M}^{S}+\right.$ $\left.d_{F F}^{S}\right)+q_{2}\left(1-\alpha_{2}\right) d_{00}+\rho\left(d_{F F}^{N}+d_{M F}^{N}+d_{F F}^{S}+d_{M F}^{S}\right)+\lambda_{2}\left(d_{F F}^{S}+d_{M F}^{S}\right)$.

Next we investigate the exits of firms from the state $d_{0 F}$. On the one hand, senior managers may be exit the market at rate $\rho$ rendering the firm empty $\left(d_{00}\right)$. On the other hand, firms may fill their open mid-level position with a female worker, which happens at rate $\bar{q}_{1}^{F F}$, or with a male worker, which happens at rate $\bar{q}_{1}^{M F}$. Note that these rates include the possibility of formal and referral hiring to mid-level positions. So the exit of firms from the state $d_{0 F}$ is given by: $\left(\rho+\bar{q}_{1}^{F F}+\bar{q}_{1}^{M F}\right) d_{0 F}$. This yields the following differential equations for $d_{0 F}$ and $d_{0 M}$ :

$$
\begin{aligned}
\dot{d}_{0 F} & =\underbrace{d_{F 0}(\bar{x})+\rho\left(d_{F M}^{S}+d_{F F}^{S}\right)}_{\text {promotions of mid-level workers }}+\underbrace{q_{2}\left(1-\alpha_{2}\right) d_{00}}_{\text {outside hiring into senior position }} \\
& +\underbrace{\rho\left(d_{F F}^{N}+d_{M F}^{N}+d_{F F}^{S}+d_{M F}^{S}\right)}_{\text {exit of mid-level workers }}+\underbrace{\left(\bar{q}_{1}^{F F}+\bar{q}_{1}^{M F}\right) d_{0 F}}_{\begin{array}{c}
\text { mid-level workers quitting } \\
\lambda_{2}\left(d_{F F}^{S}+d_{M F}^{S}\right)
\end{array}} \\
& -\quad \underbrace{\rho d_{0 F} \quad-} \underbrace{\left(\bar{q}_{1}\right.}_{\text {exit of senior managers }} \text { formal and referral hiring of mid-level workers } \\
\dot{d}_{0 M} & =d_{M 0}(\bar{x})+\rho\left(d_{F M}^{S}+d_{M M}^{S}\right)+q_{2} \alpha_{2} d_{00}+\rho\left(d_{M M}^{N}+d_{F M}^{N}+d_{M M}^{S}+d_{F M}^{S}\right) \\
& +\lambda_{2}\left(d_{M M}^{S}+d_{F M}^{S}\right)-\rho d_{0 M}-\left(\bar{q}_{1}^{M M}+\bar{q}_{1}^{F M}\right) d_{0 M}
\end{aligned}
$$

In this paper we restrict our attention to steady state equilibria, so we set $\dot{d}_{00}=\dot{d}_{M F}^{S}=\dot{d}_{F M}^{S}=$ $\dot{d}_{M M}^{S}=\dot{d}_{F F}^{S}=\dot{d}_{0 F}=\dot{d}_{0 M}=0$. Given that this system of equations is over-identified, we substitute one of the equations by fixing the total number of firms $d$. This is an exogenous parameter, which yields:

$d_{00}+d_{F 0}+d_{M 0}+d_{0 F}+d_{0 M}+d_{M M}^{N}+d_{M F}^{N}+d_{F M}^{N}+d_{F F}^{N}+d_{M M}^{S}+d_{M F}^{S}+d_{F M}^{S}+d_{F F}^{S}=d(13$

Solving equations (3)-(13) in the steady state we find the equilibrium distribution of firms $\left\{d_{00}, d_{F 0}, d_{M 0}, d_{0 F}, d_{0 M}, d_{F M}^{N}, d_{F F}^{N}, d_{M F}^{N}, d_{M M}^{N}, d_{F M}^{S}, d_{F F}^{S}, d_{M F}^{S}, d_{M M}^{S}\right\}$. Based on the above distribution of firms, we can immediately calculate the distribution of male and female workers in different job levels. Recall that the absolute numbers of workers in different job levels are denoted by $e_{0}^{j}, e_{1}^{j}$ and $e_{2}^{j}, j=M, F$, so we get:

$$
\begin{array}{llll}
e_{1}^{F}=d_{F F}^{N}+d_{F 0}+d_{F M}^{N}+d_{F M}^{S}+d_{F F}^{S} & e_{1}^{M}=d_{M M}^{N}+d_{M 0}+d_{M F}^{N}+d_{M F}^{S}+d_{M M}^{S} \\
e_{2}^{F}=d_{F F}^{N}+d_{0 F}+d_{M F}^{N}+d_{M F}^{S}+d_{F F}^{S} & e_{2}^{M}=d_{M M}^{N}+d_{0 M}+d_{F M}^{N}+d_{F M}^{S}+d_{M M}^{S}
\end{array}
$$

Finally, let variables $p_{0}^{j}, p_{1}^{j}$ and $p_{2}^{j}, j=M, F$ denote the distribution of workers across different hierarchical levels of firms, that is $p_{2}^{M}=e_{2}^{M} /(1-h), p_{1}^{M}=e_{1}^{M} /(1-h), p_{0}^{M}=1-p_{1}^{M}-p_{2}^{M}$. And same for female workers: $p_{2}^{F}=e_{2}^{F} / h, p_{1}^{F}=e_{1}^{F} / h, p_{0}^{F}=1-p_{1}^{F}-p_{2}^{F}$. So $p_{2}^{F}$ here is the fraction of female workers in senior managerial positions, whereas $p_{2}^{M}$ is the corresponding fraction for male workers. 


\section{Numerical results}

\subsection{Benchmark setting}

This section is dedicated to the numerical analysis of the model. We start by setting values of the parameter vector $\left\{\rho, h, d, \bar{x}, z_{1}, z_{2}\right\}$. We follow the traditional approach in search theory and interpret one period of time as one quarter. We choose $\rho=0.015$, which implies that the average employment duration in management jobs (level 1 and 2 ) is $1 /(4 \cdot \rho)=16.6$ years. Model I is our benchmark model where both gender groups have equal size, that is $h=0.5$. In the following analysis we also consider participation rates in the range [0.3..0.5]. Parameter $\bar{x}$ takes values in the range [40..60] with a benchmark case $\bar{x}=50$, this means that firms require at least $50 / 4=12.5$ years of experience for promoting mid-level workers to senior positions. Next we set $d=0.3$ meaning that there are 300 two-level firms in the labour market with 1000 workers. This leads to potentially $300 \cdot 2=600$ management jobs. In the model without search frictions and without experience requirement $\bar{x}$ this would imply that $60 \%$ of (high skill full-time employed) workers perform management jobs. In this situation, matching parameters $z_{1}$ and $z_{2}$ allow us to replicate the empirically observed distribution for Germany presented in Table 1. So we use values $z_{1}=0.0135$ and $z_{2}=0.2$ in order to reproduce the distribution $p_{0}=0.54, p_{1}=0.25$, $p_{2}=0.21$. These numbers indicate that only $46 \%$ of workers are performing management jobs in a frictional economy rather than $60 \%$. Intuitively, this implies that 140 out of 600 management jobs remain vacant on average due to the experience requirement in senior jobs and search frictions. Our benchmark parameter choices are summarized in Table 2.

Table 2: Benchmark parameters: 1 period $\approx 1$ quarter

\begin{tabular}{c|c|l}
\hline Parameter & Value & Explanation \\
\hline \hline$\rho$ & 0.015 & Worker exit rate / Job destruction rate \\
$h$ & 0.500 & Fraction of female workers \\
$\bar{x}$ & 50 & Experience level necessary for promotion \\
$d$ & 0.3 & Total number of firms per worker \\
$z_{1}$ & 0.0135 & Search intensity of workers in low level jobs \\
$z_{2}$ & 0.2 & Search intensity of workers in mid-level jobs \\
\hline
\end{tabular}

Our benchmark model - Model I - is summarized in columns (1)-(2) of Table 3. This is the model without referrals $(s=0)$ and with equal participation of males and females $(h=0.5)$. The equilibrium transition rates $\lambda_{1}=0.0127$ and $\lambda_{2}=0.1993$ can be interpreted in the following way. On average individuals spend $1 /\left(4 \cdot \lambda_{1}\right)=20$ years in non-management jobs before they become managers. So if some young individual enters the labour market at the age of 18 years, then this person becomes a mid-level manager on average at the age of 38 years. Further, firms require 12.5 years of experience in mid-level jobs before these workers become eligible for positions in senior management. This means, on average, individuals reach the age of 50.5 years when they are considered as sufficiently experienced to take a senior position. Some of these employees are immediately promoted by firms within companies whereas others have to wait for a vacant senior position in their firm, which happens at rate $\rho$, and search externally. So most workers are at the age of 51-52 years when they take a senior job. We can also see that $q_{1}=0.1374$ is larger than $q_{2}=0.0181$. This means that it is much easier for firms to hire mid-level managers than senior 
managers. This is also reflected in the fact that there are more firms without a senior manager $d_{10}=0.0806$ compared to the number of firms without a mid-level worker $d_{01}=0.0385$. The numbers of firms are reported per worker. So $d_{10}=0.0806$ implies approximately 81 firms in a labour market with 1000 workers.

Table 3: Equilibrium values of endogenous variables. Parameters: $\rho=0.015, \bar{x}=50, z_{1}=$ $0.0135, z_{2}=0.2, d=0.3$

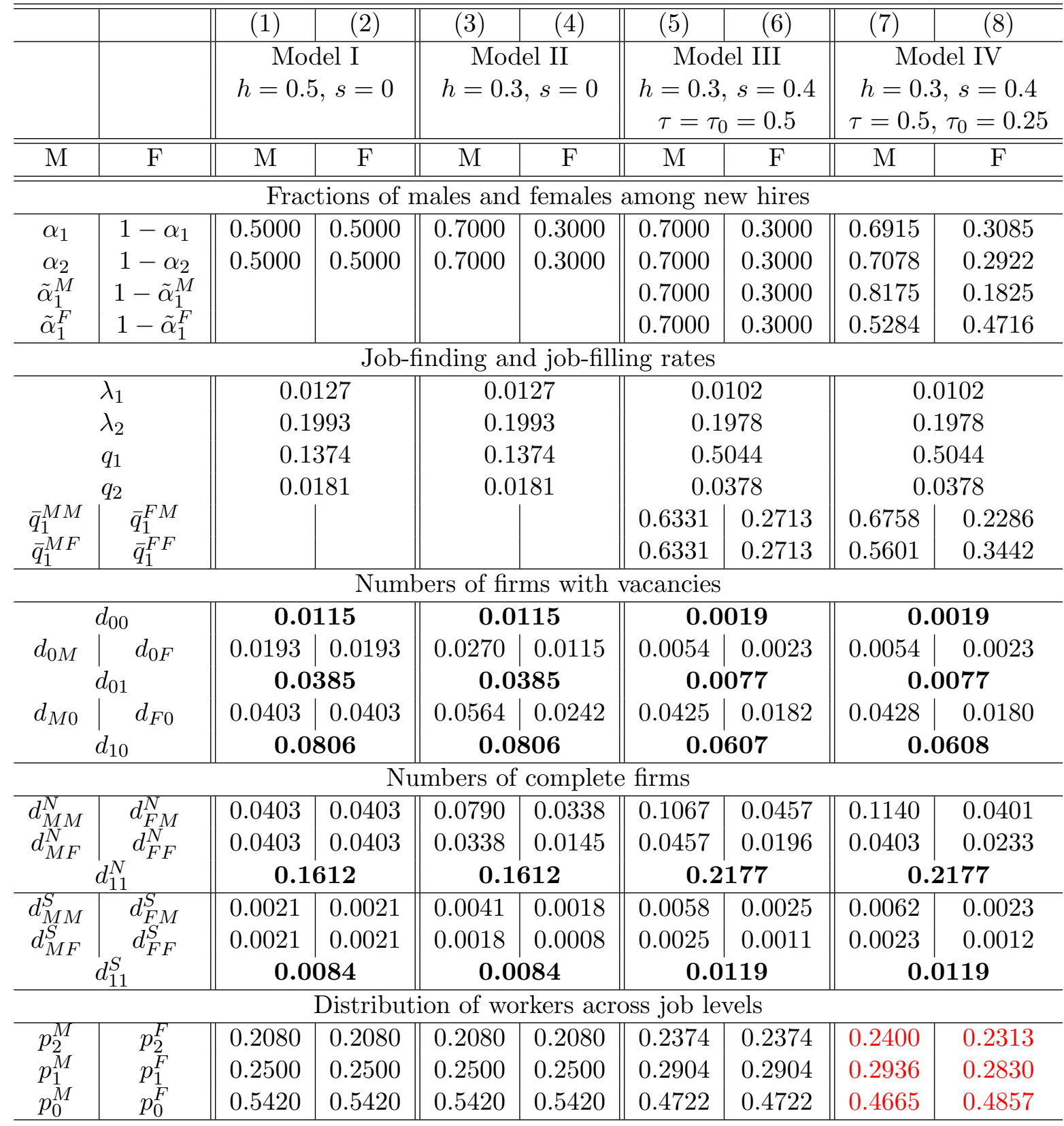

In the next step we make the model more realistic by reducing the fraction of women in the market. From German labour market data,SOEP (2013), we know that the fraction of high skill women performing full-time jobs varies between 18-20\% in the energy and construction sector, and $45-48 \%$ in retail trade and non-financial services. In the middle range there is manufacturing, financial services and transportation with $26-33 \%$ of women. Following this empirical evidence we set the fraction of female workers in our model equal to $h=0.3$. This means that $70 \%$ of 
workers in the market are males $M$. This is Model II and it is summarized in columns (3)-(4) of Table 3. Recall that $\alpha_{1}$ is a probability that the applicant to the mid-level position is of type $M$. Given that $M$ workers are the majority in Model II it is intuitive that $\alpha_{1}=0.7$. This merely reflects that fact that there are $70 \%$ type $M$ workers in the economy. There are also more firms with male managers: $d_{M 0}=0.0564>d_{F 0}=0.0242$ and $d_{0 M}=0.0270>d_{0 F}=0.0115$. However, this does not affect the chances of male and female workers in terms of upward mobility. So the distributions $p_{2}, p_{1}$ and $p_{0}$ are identical between male and female workers indicating equal career opportunities despite the fact that female workers are the minority.

\subsection{Network composition}

In this section we analyze the structure of social networks in our model. Social networks are driven by the following vector of parameters $\left\{\phi, \delta, \tau, \tau_{0}\right\}$. Recall that the average number of directed links of a male worker to other males is given by $\psi_{M M}=\frac{\phi}{\delta} \tau(1-h)$, whereas the average number of links to female workers is given by $\psi_{M F}=\frac{\phi}{\delta} \tau_{0} h$. So the total number of contacts in the network of a male worker is given by $n_{M}=\psi_{M M}+\psi_{M F}=\frac{\psi}{\delta}\left[\tau(1-h)+\tau_{0} h\right]$.

Here again we start by considering the situation with equal participation of males and females $h=1-h=0.5$ and no gender homophily, that is $\tau=\tau_{0}$. So the total average number of contacts for male and female workers is given by $n_{M}=n_{F}=\frac{\psi}{\delta} \tau$. Cingano and Rosolia (2012) report that the number of social connections between individuals in Italy is about 32. Glitz (2017) reports a similar number for Germany with approximately 43 social contacts. Thus, we set parameters $\psi=0.8, \delta=0.01$ and $\tau=0.5$ in order to obtain the average number of social links in the benchmark model equal to $0.8 \cdot 0.5 / 0.01=40$. This means that a given person meets another one with probability $\phi=0.8$ per unit time and includes this new person into the network with probability 0.5 . On average every person creates 0.4 social links per unit time. Every link is destroyed with probability $\delta=0.01$. With an average number of social links equal to 40 , this means that individuals lose $40 \cdot 0.01=0.4$ links per unit time. Thus, the social network is balanced in the equilibrium.

With equal proportions of male and female workers $h=0.5$ and no gender homophily $\left(\tau=\tau_{0}\right)$ we get that half of the links are with workers of the same (opposite) gender. This is illustrated in panel (A) of Table 4. Next we reduce participation of female workers, so that $h=0.3$. This case is illustrated in panel (B). Since there is still no homophily in this setting, lower participation of female workers leads to a lower fraction of female workers in the networks of males and other females. For example, we can see that both genders now have only a fraction $1-\gamma_{M}=\gamma_{F}=12 / 40$ of female workers in their networks, which is exactly $30 \%$. Figure 1 (left) shows the corresponding Poisson distributions of social networks, where the left density illustrates links of both genders to female workers and the right density illustrates links of both genders to male workers. These distributions only reflect the fact that female workers are the minority in panel (B).

Further we return to the setting with equal participation $h=0.5$ and analyze the implications of gender homophily, illustrated in panel (C). Here we set $\tau_{0}=0.25<\tau=0.5$. We justify our choice of the homophily parameter $\tau_{0}$ in the next section when we combine networks and referral hiring. Panel (C) reveals that gender homophily is erasing half of the cross-gender links and their average number falls from 20 down to 10 . This also reduces the average total number of 
Table 4: Network composition for different parameter values

\begin{tabular}{c|c|c|l}
\hline & $\mathrm{M}$ & $\mathrm{F}$ & Total \\
\hline $\mathrm{M}$ & 20 & 20 & 40 \\
$\mathrm{~F}$ & 20 & 20 & 40 \\
\hline \multicolumn{7}{l}{$(\mathrm{A}): h=0.5, \tau=\tau_{0}=0.5$}
\end{tabular}

\begin{tabular}{c|c|c|l}
\hline & $\mathrm{M}$ & $\mathrm{F}$ & Total \\
\hline $\mathrm{M}$ & 20 & 10 & 30 \\
$\mathrm{~F}$ & 10 & 20 & 30 \\
\hline \multicolumn{4}{l}{$(\mathrm{C}): h=0.5, \tau=0.5}$,
\end{tabular}

\begin{tabular}{c|c|c|l}
\hline & $\mathrm{M}$ & $\mathrm{F}$ & Total \\
\hline $\mathrm{M}$ & 28 & 12 & 40 \\
$\mathrm{~F}$ & 28 & 12 & 40 \\
\hline
\end{tabular}

(B): $h=0.3, \tau=\tau_{0}=0.5$

\begin{tabular}{c|c|c|l}
\hline & $\mathrm{M}$ & $\mathrm{F}$ & Total \\
\hline $\mathrm{M}$ & 28 & 6 & 34 \\
$\mathrm{~F}$ & 14 & 12 & 26 \\
\hline
\end{tabular}

(D): $h=0.3, \tau=0.5, \tau_{0}=0.25$

links in the social network down to 30. The corresponding Poisson densities are illustrated on Figure 1 (right) where the dashed curve corresponds to cross-gender connections. We can see that only $10 / 30$, that is about $33 \%$ of links in the networks of male workers are with female workers, even though both gender groups have the same size in $(\mathrm{C})$. The situation is symmetric and there are only $33 \%$ of links to male workers in the networks of females.
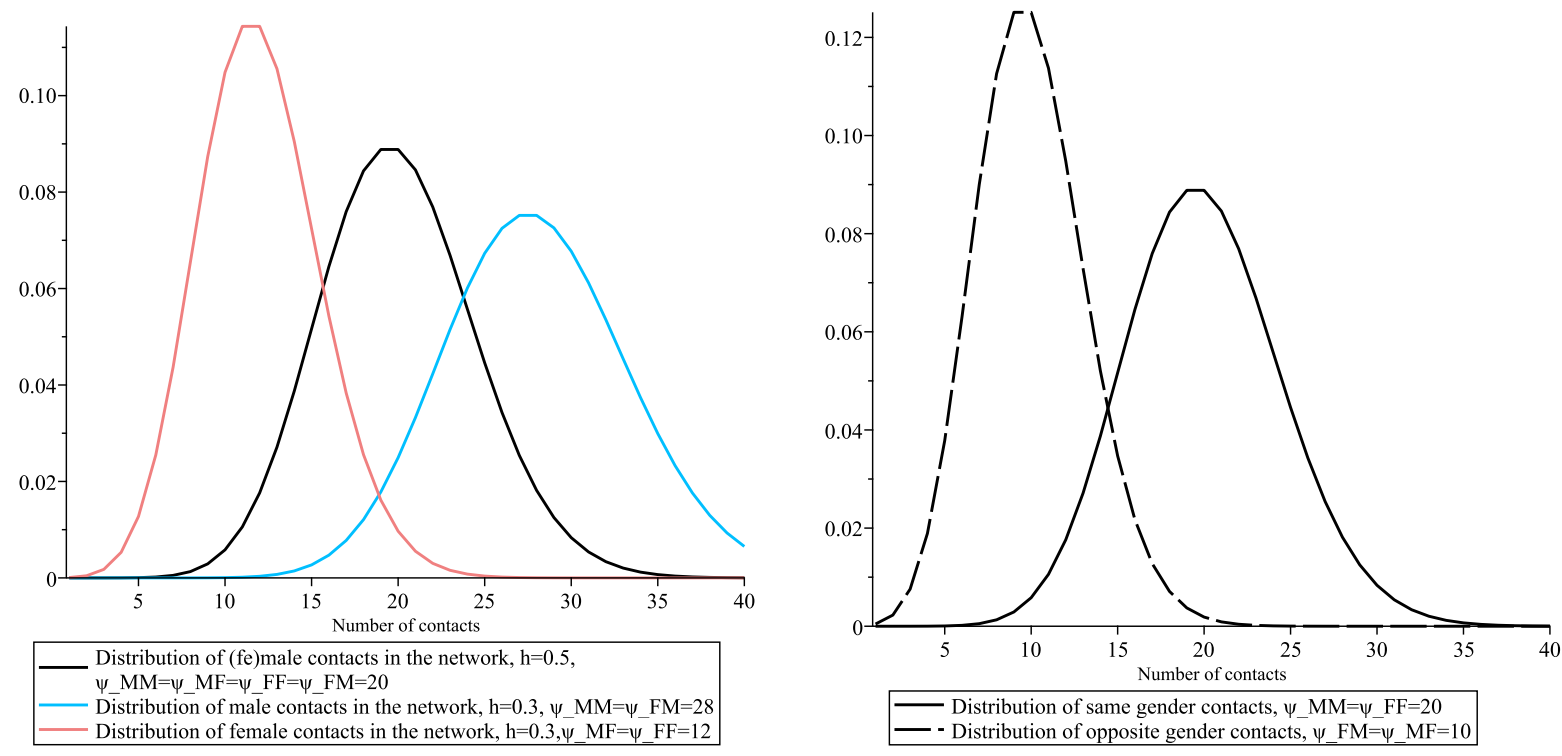

Figure 1: Left: Effect of the participation rate $h$. Right: Effect of the gender homophily $\tau_{0}$

Finally, we combine the two effects and consider the situation with $h=0.3$ (lower participation of females) and $\tau_{0}=0.25$ (gender homophily). This case is contained in part (D) of Table 4. We can see that lower participation of female workers leads to $\psi_{M M}=28$ and $\psi_{F F}=12$ as in case (B). At the same time gender homophily is erasing half of the potential cross-gender contacts, so that $\psi_{M F}=6$ and $\psi_{F M}=14$ as in case (C). One direct consequence of the combined effect is that female workers end up with smaller social networks $\left(n_{F}=26<n_{M}=34\right)$. Moreover, the fraction of female contacts in the networks of males is only $6 / 34$, that is $17.6 \%$, which is well below the population average of $30 \%$. The reason is two-fold, on-the-one hand, female workers are the minority and, on-the-other hand, it is more difficult to create connections with the opposite gender. At the same time the fraction of male contacts in the networks of females is $14 / 26$, that is $53.8 \%$, which is well below the population average of males equal to $70 \%$. The corresponding four densities are illustrated in Figure 2. Due to the inherent property of the 
Poisson distribution larger mean is associated with a larger variance. The figure reveals that the standard deviation of the male distribution of male contacts $\sqrt{\psi_{M M}}=\sqrt{28} \approx 5.3$ is much larger than the standard deviation in the distribution of female contacts $\sqrt{\psi_{M F}}=\sqrt{6}=2.4$. So the former distribution is more dispersed.

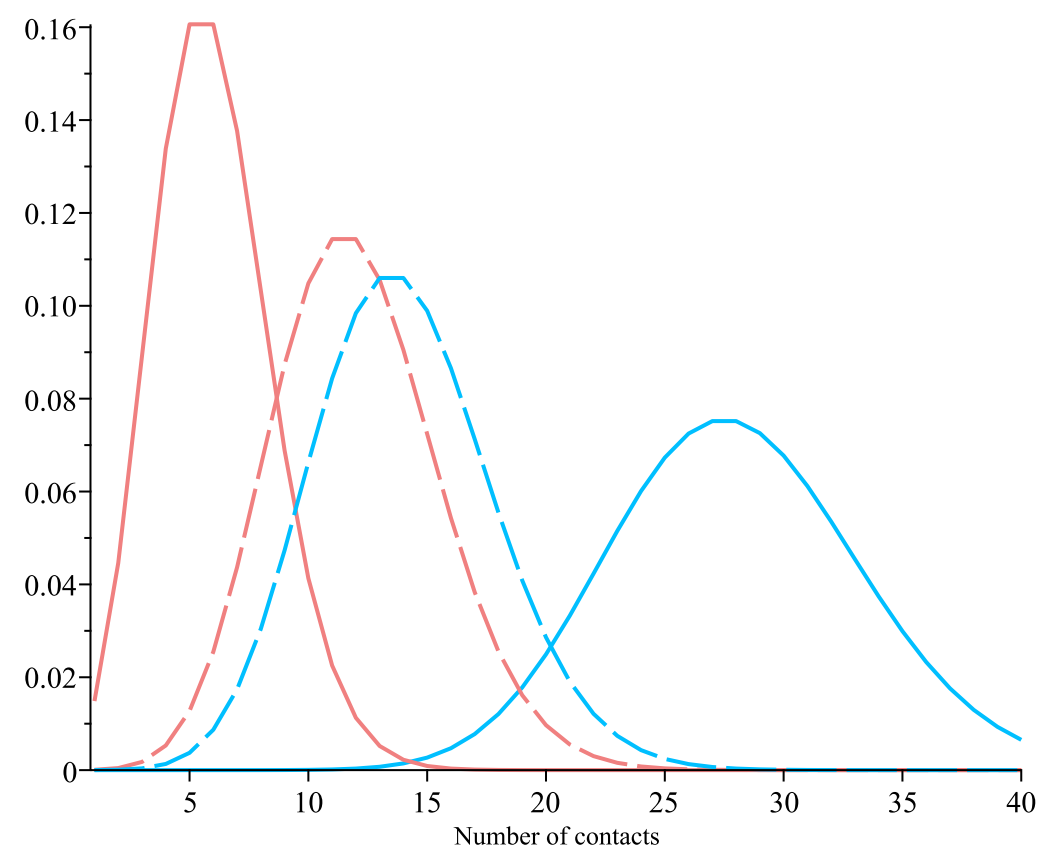

Distribution of male contacts in the network of a male worker, $\psi_{-} \mathrm{MM}=28$
Distribution of female contacts in the network of a male worker, $\psi_{-} \mathrm{MF}=6$
- Distribution of female contacts in the network of a female worker, $\psi_{-} \mathrm{FF}=12$
- Distribution of male contacts in the network of a female worker, $\psi_{-} \mathrm{FM}=14$

Figure 2: Network densities with gender homophily and lower participation of female workers

\subsection{Referral hiring}

In this section we incorporate social networks into the model and analyse the implications of referrals. First, we set $s=0.4$, which is the probability that the senior manager is asked to recommend a contact for the open mid-level position. This parameter is driving the frequency of referral hiring. Here we follow the empirical literature (Pistaferri, 1999; Addison and Portugal, 2002; Bentolila et al., 2010; Pellizzari, 2010), which reports that 30\%-50\% of employees are hired via referrals. For Germany Rebien et al. (2017) show that the average fraction of referral hires in the years 2012-2015 is equal to $37 \%$.

Model III in Table 3 (columns (5)-(6)) shows the equilibrium with referral hiring, lower participation of female workers $(h=0.3)$ but no gender homophily $\left(\tau=\tau_{0}=0.5\right)$. This network type corresponds to case (B) in the previous section. Intensive referral hiring has a strong impact on the labour market. We can see that the total job-filling rate is relatively high: $\bar{q}_{1}^{M M}+\bar{q}_{1}^{F M}=0.9044$, indicating that firms with open mid-level positions enjoy $90.44 \%$ probability of filling their position per unit time. This number does not depend on the gender of the senior manager since $\bar{q}_{1}^{M F}+\bar{q}_{1}^{F F}=0.9044$ and it is much higher than the job-filling rate in the model without referrals (Model II) where the job-filling rate of mid-level positions was only 0.1374 . Note, that the total job-filling rate $\bar{q}_{1}^{M M}+\bar{q}_{1}^{F M}$ consists of the formal hiring rate 
$q_{1}=0.5044$ and the referral hiring rate $\tilde{q}_{1}^{M}=0.4$, so the average fraction of employees hired by recommendation can be evaluated at $0.4 / 0.9044 \approx 0.44$, that is $44 \%$.

Model III reveals that the general equilibrium effect is amplifying the consequences of referral hiring. Since many firms fill their positions via referrals there are less open vacancies for midlevel jobs $d_{00}+d_{01}$. This reduces the competition of firms in the formal hiring process and leads to the higher job-filling rate $q_{1}=0.5044>0.1374$ (see Equation (1)). So referral hiring reduces the number of firms with empty positions $d_{00}+d_{01}+d_{10}$ which was 0.1306 in Model II and raises the number of firms with full employment $d_{11}^{N}+d_{11}^{S}$ which was 0.1696 . The numbers in Model III are now 0.0703 and 0.2297 . Intuitively, this means that in the equilibrium there are 60 firms more with full employment (per 1000 workers) due to referral hiring.

Network hiring also has strong implications for workers as shown in the last rows of Table 3. Workers move much faster from level 0 to level 1, so the average fraction of workers in the lowast level is reduced to $47.22 \%$, while the fraction of workers in midddle management is increased to $29.04 \%$. Even though firms still require $\bar{x}$ periods of experience for senior management jobs, more workers start accumulating experience on average and so more workers reach the highest positions. Finally, Model III reveals that neither differences in the participation rates nor referral hiring give rise to position differences between male and female workers. Even though female workers are the minority and both genders are involved into referral hiring, upward mobility patterns and opportunities are still the same for both groups of workers.

Further, we investigate the consequences of network hiring with homophilous social networks in Model IV (columns (7)-(8) of Table 3). Conditional on the probability of referral hiring, male senior managers are more likely to recommend male applicants which happens with probability $\tilde{\alpha}_{1}^{M}=0.8175$. This probability is substantially higher than the population average of male workers 0.7 . In a similar way, female senior managers tend to over-recommend female job candidates with the corresponding probability $1-\tilde{\alpha}_{1}^{F}=0.4716$, which is well above the population average of female workers equal to 0.3. These numbers are similar to the empirical findings of Fernandez and Sosa (2005). They find that both genders tend to over-recommend their own types by about $10 \%$ compared to the fraction of their gender among external applicants. This confirms our choice of the homophily parameter $\tau_{0}=0.25$.

If the senior manager in the firm is a male worker, than the rate at which the open mid-level job is filled with a male applicant is increasing to $\bar{q}_{1}^{M M}=0.6758$ compared to Model III and the rate at which this position is filled with a female worker is decreasing to $\bar{q}_{1}^{F M}=0.2286$. In contrast, if the senior manager is a female worker, then the rate at which the job is filled with a male candidate is decreasing to $\bar{q}_{1}^{M F}=0.5601$, while the rate at which this position is filled with another female candidate is increasing to $\bar{q}_{1}^{F F}=0.3442$. One important point to be emphasized is that there are relatively many firms with a male senior manager $d_{0 M}=0.0054$ and relatively few firms with a female senior manager $d_{0 F}=0.0023$. This is due to the fact that female workers are the minority. Thus lower participation of female workers, combined with intensive referral hiring and network homophily benefits and improves career opportunities of the majority male group, while worsening the chances of the minority female group. This leads to the more beneficial distribution of male workers with $46.65 \%$ of male workers remaining in low level jobs on average and $24 \%$ becoming senior managers compared to $48.57 \%$ of female workers in the bottom and $23.13 \%$ in senior management. Therefore, we conclude that a combination 
of three factors - lower participation of females, referral hiring and network homophily - can generate the glass-ceiling effect even in the absence of direct discrimination.

\subsection{Comparative statics}

In this subsection, we perform comparative statics analyses and investigate which factors mitigate or amplify the glass-ceiling effect generated in Model IV. First, we vary the female participation rate $h$ in the range [0.3..0.5] and calculate the fractions of male and female workers in lowest and highest positions. The left panel of Figure 3 shows fractions $p_{0}^{F}$ and $p_{0}^{M}$. We can see that these fractions are the same and equal to 0.4722 as a long as both groups are equally large $(h=0.5)$. The difference appears as soon as $h$ falls below 0.5 and the gap is increasing with lower values of $h$, which means that more and more female workers remain in low level jobs compared to male workers. For $h=0.3$ we reach the values of Model IV with $p_{0}^{F}=0.4857$ and $p_{0}^{M}=0.4665$. The right panel of Figure 3 shows fractions of male and female worker in senior positions, that is $p_{2}^{F}$ and $p_{2}^{M}$. Again there are no differences between the two gender groups as long as $h=0.5$. The gap is generated as soon as $h<0.5$ and it is increasing with lower $h$ reaching the levels $p_{2}^{F}=0.2313$ and $p_{2}^{M}=0.2400$ for $h=0.3$. These numbers correspond to Model IV in Table 3. Overall, we conclude that lower participation of female workers generates a stronger disadvantage in terms of professional networks for female workers and amplifies the glass-ceiling effect.
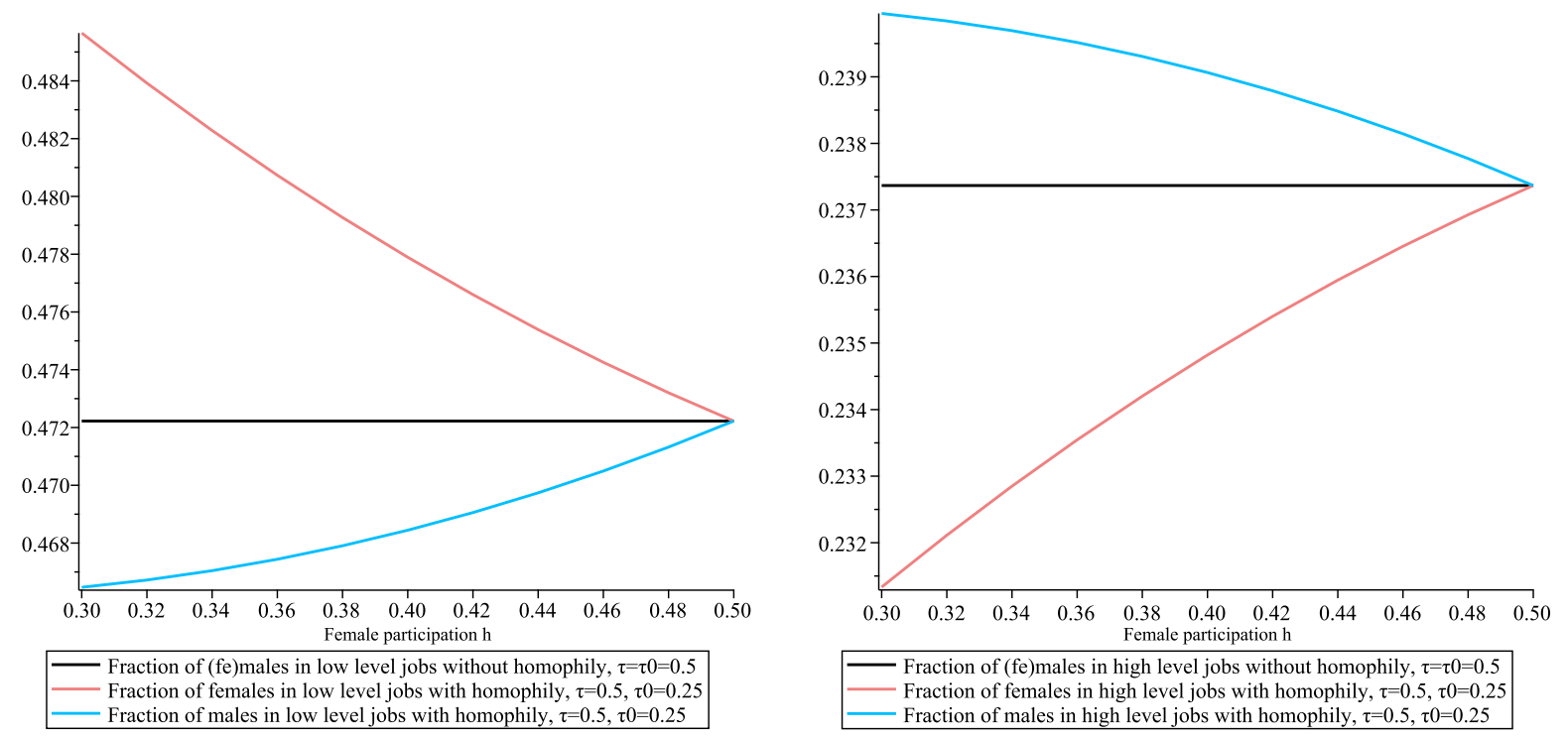

Figure 3: Comparative statics with respect to female participation fraction $h$. Left: fraction of employees on level 0 within their gender group, $p_{0}^{F}$ and $p_{0}^{M}$. Right: fraction of employees on level 2 within their gender group, $p_{2}^{F}$ and $p_{2}^{M}$.

Next we perform comparative statics analysis with respect to parameter $s$, which is the probability that the senior manager is asked to recommend one of his/her contacts for the open mid-level position. Indirectly this parameter is driving the frequency of referral hires. Figure 4 shows fractions $p_{0}^{F}$ and $p_{0}^{M}$ and $p_{2}^{F}$ and $p_{2}^{M}$ for $s$ in the interval [0..0.4]. On the left panel we can see that there are no differences between the two gender groups for $s=0$. This is the case without referrel hiring, where $p_{0}^{F}=p_{0}^{M}=0.5422$. The differences appear as soon as $s>0$ and 
the gap is increasing for larger values of $s$ indicating more intensive referrals. When $s=0.4$ we obtain the values of Model IV with $p_{0}^{F}=0.4857$ and $p_{0}^{M}=0.4665$. The right panel shows fraction $p_{2}^{F}$ and $p_{2}^{M}$. Here we can see that fewer female workers reach senior positions with more intensive referral hiring.
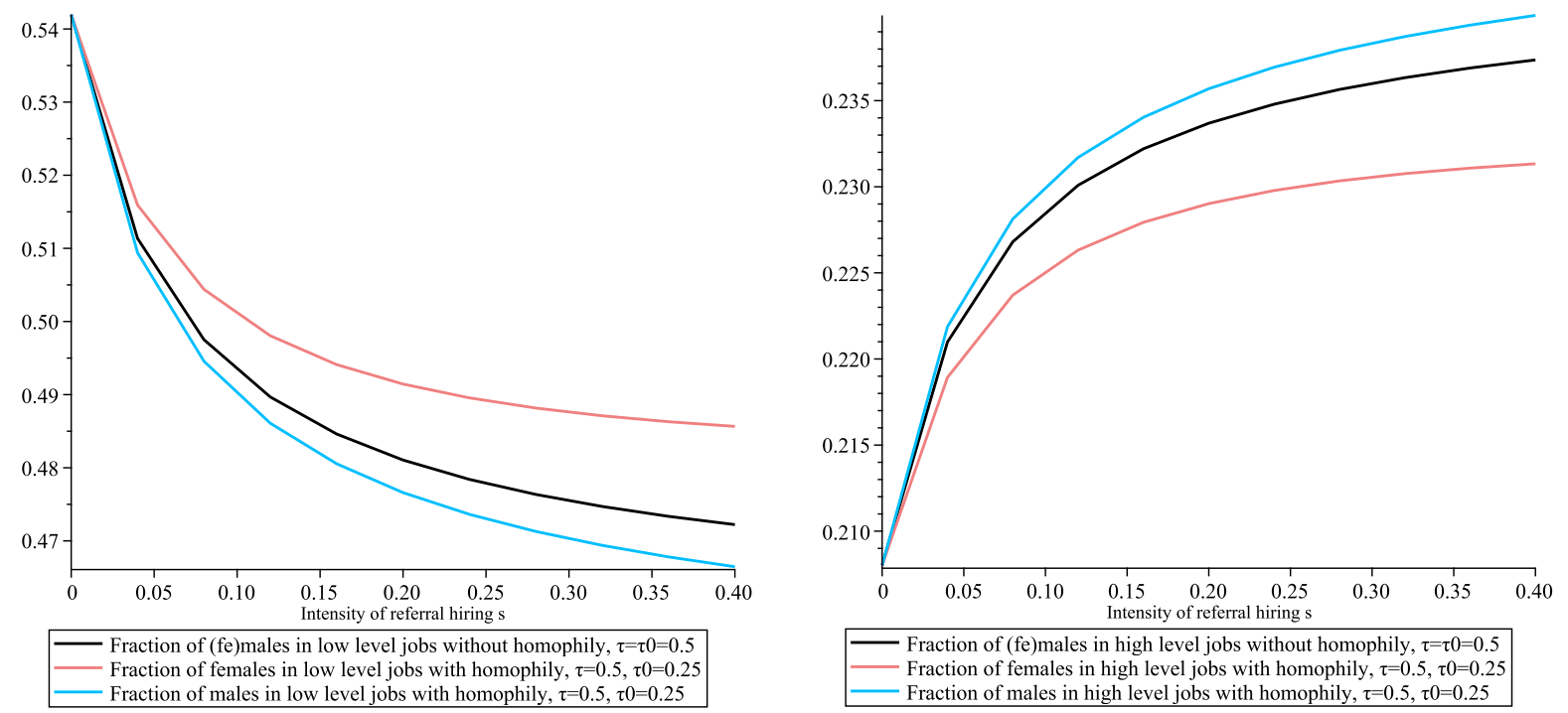

Figure 4: Comparative statics with respect to the referral intensity $s$. Left: fraction of employees on level 0 within their gender group, $p_{0}^{F}$ and $p_{0}^{M}$. Right: fraction of employees on level 2 within their gender group, $p_{2}^{F}$ and $p_{2}^{M}$.

The previous analysis shows that lower participation of female workers and more intensive referral hiring contribute to larger differences in the distributions of male and female workers. The question remains how much of the empirically observed wage gap due to the glass-ceiling effect in Germany $(6.4 \%)$ can be explained by Model IV? To answer this question we take normalised wages from table 1 and assign these wages to the three hierarchical levels in our model, so that $w_{0}=1, w_{1}=1.319$ and $w_{2}=1.713$. With these wages we can calculate the average wages of male and female workers in our model:

$$
\begin{aligned}
w^{F} & =p_{0}^{F} w_{0}+p_{1}^{F} w_{1}+p_{2}^{F} w_{2}=0.4857 \cdot 1+0.2830 \cdot 1.319+0.2313 \cdot 1.713=1.254 \\
w^{M} & =p_{0}^{M} w_{0}+p_{1}^{M} w_{1}+p_{2}^{M} w_{2}=0.4665 \cdot 1+0.2936 \cdot 1.319+0.2400 \cdot 1.713=1.264
\end{aligned}
$$

The wage gap generated by Model IV is equal to $1.264 / 1.254-1=0.008$, that is $0.8 \%$. We can see that the gender wage gap depends on the distributions $p_{i}^{F}, p_{i}^{M}$ and on the fixed wages $w_{i}$, $i=0,1,2$. Recall that the distributions $p_{i}^{F}, p_{i}^{M}$ reflect upward mobility of workers by means of on-the-job search and internal promotions. Moreover, the spead of internal promotions depends on the promotion time $\bar{x}$. Figure 5 illustrates the relative gender wage gap $\left(w^{M}-w^{F}\right) / w^{F}$ as a function of the promotion cut-off $\bar{x}$. We vary this parameter in the range [40..60] with the benchmark value $\bar{x}=50$, corresponding to 12.5 years. The corresponding function is downwardsloping, which means that earlier promotions amplify the wage difference generated by social networks and referral hiring.

Finally, we can also see that the relative gender wage gap strongly depends on the fixed wages $w_{i}, i=0,1,2$. To understand this dependence we vary the mid-level wage $w_{1}$ on Figure 


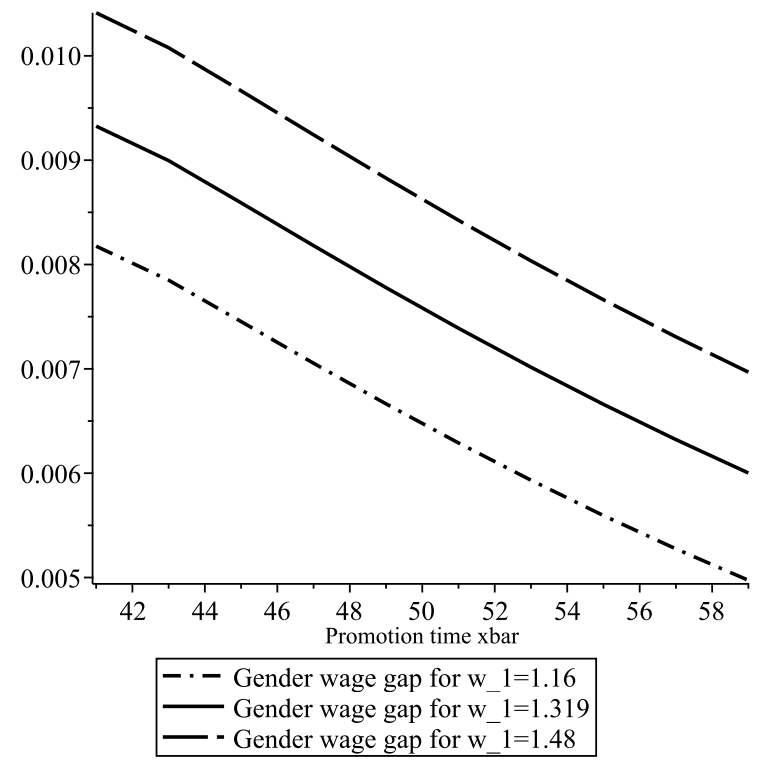

Figure 5: Relative gender wage gap $\left(w^{M}-w^{F}\right) / w^{F}$ as a function of the promotion cut-off $\bar{x}$ and mid-level wage $w_{1}$.

5. In particular, we consider $w_{1}=1.16$ which is lower than the benchmark case $\left(w_{1}=1.319\right)$ and $w_{1}=1.48$ which is higher than the benchmark case. We can see that higher values of $w_{1}$ shift the whole curve upwards and increase the gender wage gap. The relative gender wage gap can even be larger than $1 \%$ for higher values of $w_{1}$ and earlier promotions.

\section{Simulation model}

\subsection{Introducing extensions}

In order to study more deeply the mechanisms that underlie the glass ceiling effect in our framework we extend the model in three dimensions: (a) we add one more hierarchical level to the firms, (b) we allow for an endogenous network formation following the idea of triadic closures, and (c) introduce gender specific promotion times.

All these three extensions follow up on our general approach to study gender inequality in a framework that combines a labor market characterized by search and matching with a more elaborate representation of firms' organizational structures and hiring practices. There is ample evidence that firms organize their hierarchies distinctively (Bloom et al., 2010). It has also been shown that the nature of corporate hierarchies is changing (see, e.g. Rajan and Wulf, 2006; Guadalupe and Wulf, 2010). In particular, we refer to empirical evidence by Caliendo et al. (2015) who report that a vast majority of French firms have a hierarchical structure with up to four distinct layers. Thus, in one extension, we introduce a third top management level. Then, top level managers may refer their contacts for mid-level positions and for senior management positions. In addition, we split the overall experience requirement $\bar{x}$ of 50 time periods into two parts. So that firms require 25 periods of experience for workers to be promoted from mid-level positions to senior management and another 25 periods to become a top manager. As a result, there are three separate markets in this extended setting. It should be interesting to see whether 
deeper hierarchical structures of firms have an effect on the gender distribution in our framework, in particular, as we have also modeled networks among workers who may be referred when it comes to filling a firm's position.

The idea of triadic closures in networks in the spirit of sociologist Georg Simmel (Simmel, 1908) underlying our second extension is the following: if people A and B know each other, and at the same time people $\mathrm{B}$ and $\mathrm{C}$ know each other, then it is very likely that $\mathrm{A}$ and $\mathrm{C}$ get to know each other. Triadic closures seem to be a pertinent feature of real life networks. At least, it has been shown for various social contexts that the likelihood that $\mathrm{A}$ and $\mathrm{C}$ are connected is higher than the probability that a tie between these two is established randomly (See, e.g., Barabâsi et al., 2002; Davis et al., 2003; Holme et al., 2004; Ingram and Roberts, 2000; Newman and Girvan, 2004; Opsahl and Panzarasa, 2009; Uzzi and Spiro, 2005; Watts and Strogatz, 1998).

Finally, modeling gender specific promotion times allows us to look into the interaction between the network effect described above and direct discrimination via unequal promotion rates. The extension relates to empirical evidence suggesting that women have lower promotion probabilities (see, e.g., Cobb-Clark, 2001; Lluis, 2005; Cassidy et al., 2016). We implement discrimination along the promotion path by setting a minimum human capital level necessary for promotion $\bar{x}$ for men that is $25 \%$ lower than that for women. This reflects evidence presented in Cassidy et al. (2016) for Finnland, showing that women face a $25 \%$ lower probability of promotion. As the average duration until promotion is the inverse of the probability of promotion, we set $\bar{x}$ for men to 18.75 and leave it for women equal to 25 . Note that the three extensions are conducted sequentially and we consider the effect of unequal promotion rates in a setting with four hierarchical levels and triadic closures.

As these extensions occur to be intractable in an analytical framework we program an agentbased simulation model. Introducing the agent-based approach to the analysis of labor markets has already been proposed by Freeman (1998) some time ago. Agent-based models suit well for the formalization of set-ups which are characterized by heterogenous interacting agents. One of the earliest attempts to build an agent-based labor market model can be found in Bergmann (1990). Others followed with applications that included network structures, see, e.g., by Tassier and Menczer (2008), Stovel and Fountain (2009), Gemkow and Neugart (2011), or Dawid and Gemkow (2013). These and other contributions are surveyed in Neugart and Richiardi (2018). In order to lend credibility to our simulation model we show in Section 5.3 that the analytical results can be replicated by the agent-based simulation before we present the results on the three extensions.

\subsection{Simulation code}

Algorithm (1) outlines the pseudocode of the simulation model. ${ }^{6}$ In each of the 1000 iterations the following steps are taken. Network links are established. For the baseline simulation model that replicates the analytical results a worker meets another worker with probability $\phi=0.8$. If they are of the same gender a network link is established with probability $\tau=0.5$ and if they are of opposite gender a link is established with $\tau_{0}=0.25$. In the extension incorporating triadic closures there is a probability with which two workers meet randomly, and a counterprobability with which a particular worker meets someone from the list of contacts of one of

\footnotetext{
${ }^{6}$ The simulation code is written in Repast - a Java based platform.
} 
his or her own contacts. We set these probabilities to 0.5. After networks are formed, firms promote workers who reached the human capital level $\bar{x}$ for a vacancy (if there is one) on the next hierarchical level. The human capital level $\bar{x}$ is set to 50 for the model which replicates the analytical set-up, and to 25 for the simulation model for which we add one more hierarchical level. These human capital levels are set equal for men and women except for the extension within which we analyze discrimination along promotional paths. Here, $\bar{x}$ becomes 18.75 for men and is left equal to 25 for women. Once the internal labor markets are closed, workers apply with probability $z_{1}=0.0135$ for vacancies that do not require a certain human capital endowment, and with probability $z_{2}=0.2$ for vacancies for which they meet the human capital requirement, i.e. the senior and the top-level management positions. When hiring workers firms may consider workers with a referral. Referrals can be given by supervisors on all higher hierarchical levels. With probability $s=0.4$ supervisors on the senior and top-level management positions are invited to refer someone who is a member of their network. Next, workers' human capital is updated, and by the end of the iteration, jobs are destroyed at a rate $\rho=0.015$ and network links are dissolved at rate $\delta=0.01$. At iteration 1000 model outcomes are saved, and what we call one run is completed. In total, we simulate 50 runs which gives us a distribution of 50 observations for every outcome variable that we may analyze.

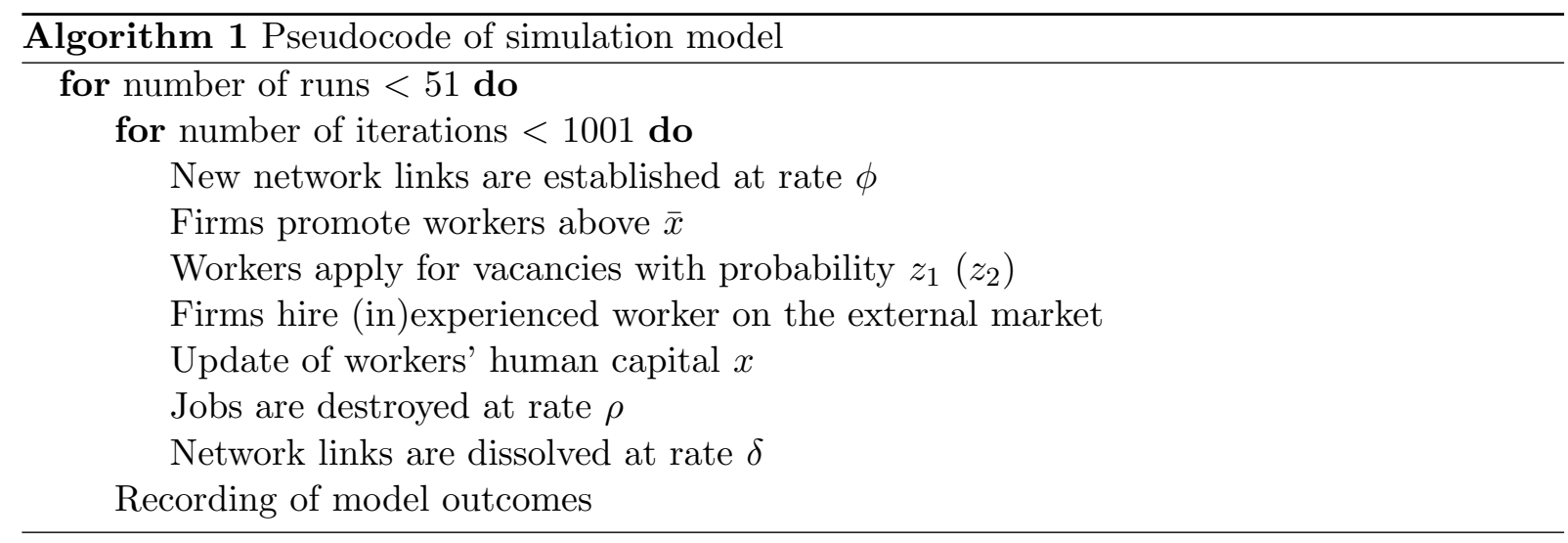

\subsection{Results}

First, we show that our simulation provides a close replication of the analytical model where we focus on specification IV (as shown in Table 3). Figure 6 illustrates the dynamics of one of the 50 runs showing the time series for selected variables over the 1000 iterations. At the beginning of the iteration all positions in the firms are vacant (panel a) and no network links exist (panel b). Eventually firms hire workers and most of the firms have both of the positions (middle and high) filled after a while. Moreover, as time evolves network links are established. Panel (b) illustrates that the numbers of network links in the simulation model quickly converge to the predicted numbers of links that male workers should have with male workers (28) or with female workers (6). The same is true for the network links of female workers. Panels (c) and (d) show the shares of males and females on the low and high positions, respectively. Again, there is convergence over time.

Making use of the 50 replications we can calculate the average values of some of the key variables in the simulation model (column (E0) in Table 5) and compare them to the outcomes 


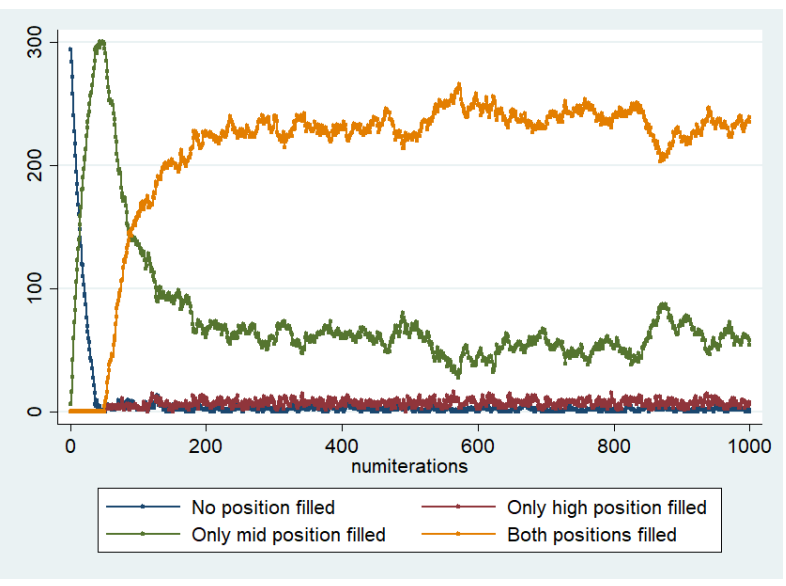

(a)

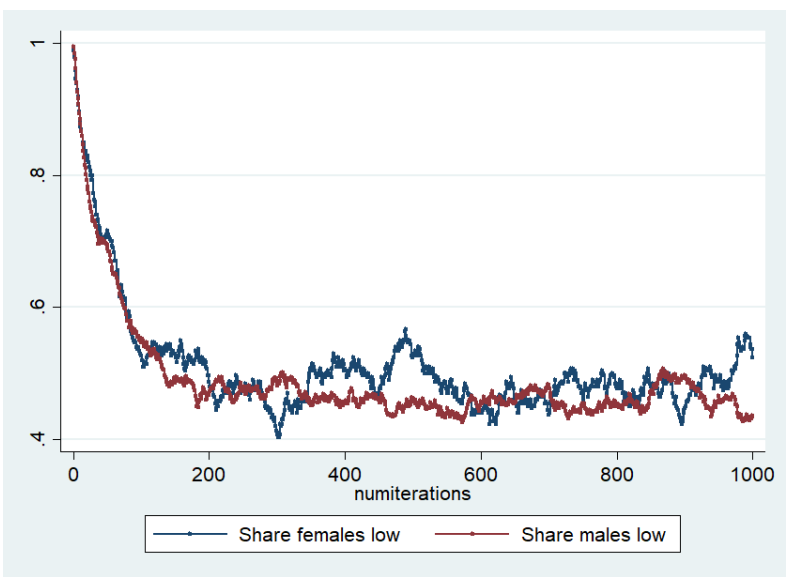

(c)

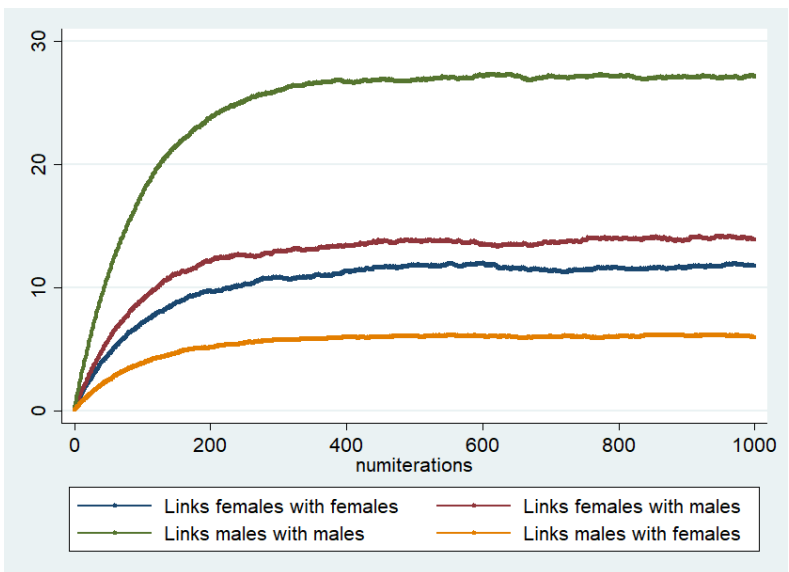

(b)

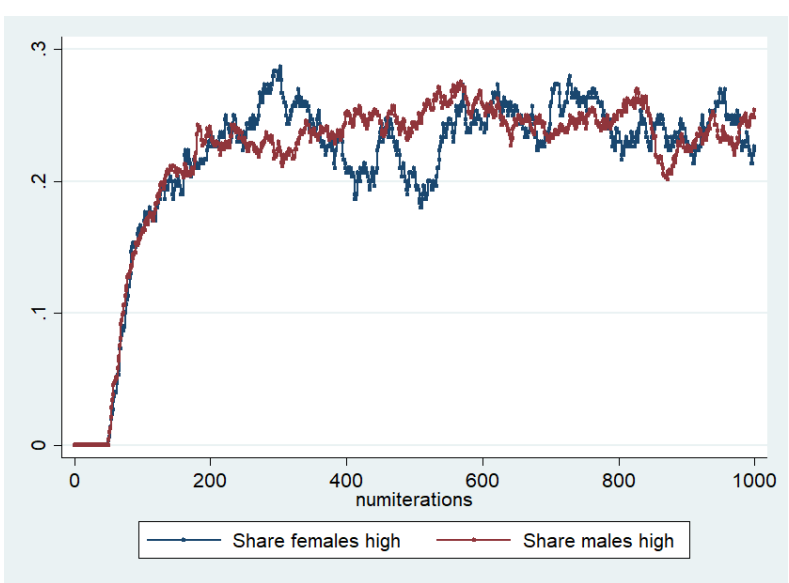

(d)

Figure 6: Time series

Notes: Times series on (a) number of firms by positions filled, (b) average number of network links by gender and direction, (c) share of employment on low level positions by gender, and (d) share of employment on high level positions by gender. Single run for 1000 iterations on Model 4. 
Table 5: Employment shares by gender and hierarchical level

\begin{tabular}{c|ccccccccc}
\hline & \multicolumn{3}{|c}{ E0 } & \multicolumn{2}{c}{ E1 } & \multicolumn{2}{c}{ E2 } & \multicolumn{2}{c}{ E3 } \\
& $\mathrm{M}$ & $\mathrm{F}$ & $\mathrm{M}$ & $\mathrm{F}$ & $\mathrm{M}$ & $\mathrm{F}$ & $\mathrm{M}$ & $\mathrm{F}$ \\
\hline \multirow{3}{*}{ low } & 0.462 & 0.485 & 0.432 & 0.464 & 0.426 & 0.480 & 0.395 & 0.463 \\
& $(0.002)$ & $(0.004)$ & $(0.002)$ & $(0.004)$ & $(0.002)$ & $(0.004)$ & $(0.002)$ & $(0.003)$ \\
middle & 0.294 & 0.287 & 0.196 & 0.182 & 0.197 & 0.181 & 0.187 & 0.196 \\
& $(0.001)$ & $(0.003)$ & $(0.001)$ & $(0.002)$ & $(0.001)$ & $(0.003)$ & $(0.001)$ & $(0.003)$ \\
& 0.243 & 0.229 & 0.169 & 0.163 & 0.172 & 0.153 & 0.204 & 0.176 \\
high & $(0.002)$ & $(0.004)$ & $(0.002)$ & $(0.003)$ & $(0.002)$ & $(0.003)$ & $(0.001)$ & $(0.003)$ \\
& - & - & 0.203 & 0.192 & 0.206 & 0.186 & 0.215 & 0.165 \\
& - & - & $(0.001)$ & $(0.003)$ & $(0.001)$ & $(0.003)$ & $(0.001)$ & $(0.003)$ \\
\hline
\end{tabular}

Notes: The table shows the mean employment shares and standard errors over 50 runs by gender and hierarchical level for the replication of the analytical model (E0), the extension to four hierarchical levels (E1), a network formation with triadic closures (E2), and gender specific promotion times with triadic closure (E3).

of the analytical model IV, see last columns of Table 3. The means of the outcome variables of the simulation model with respect to the number of firms having two, one, or no vacancy, and the shares of workers on the different jobs by gender are close to the theoretical model. In fact, they are not different from a statistical point of view. Overall, the agent-based simulation model produces results that match those of the analytical model. This makes us confident that the results of any of the three extensions to which we turn now are not due to the change from the analytical to the simulation framework.

In the next columns of Table 5 we summarize the findings of the three extensions (E1 to E3) with respect to the employment shares by gender and hierarchical level of the firms. As we go from three hierarchical levels to four (E1), the pattern in the employment shares remains. Females are less represented in the top level positions and have higher employment shares on the low level position. This is also true as we allow for a network formation in the spirit of triadic closures (E2). As can be seen from Figure 7, the network formation where workers are more likely to establish links with the contacts of workers whom they are already linked to changes the distribution of links by gender. Males tend to have fewer links with females now, but more with males. Finally, the employment pattern also remains as we add gender specific promotion times (E3) that discriminate against women.

While these findings are already interesting from a qualitative point of view one may ask, again, to which extent they are informative with respect to explaining gender wage differentials in connection with a glass ceiling effect. As before we calculate average wages for men and women based on the employment shares along the hierarchical levels of the simulation model, and the actually paid wages to men and women on these hierarchical levels that we can observe in the SOEP, c.f. Table 1. It turns out that the gender wage differential in the simulation model with three hierarchies (E0) is $0.81 \%$. Increasing the levels of hierarchy from 3 to 4 raises the gender wage differential to $1.3 \%$ (E1). Adding triadic closures to the network increases the gender wage differential further to $2.7 \%$ (E2), and, finally, including discrimination along the promotional path of a firm in terms of gender-specific human capital requirements yields a gender wage gap of $4.5 \%$. That is, without discrimination but a network with triadic closures and deeper firm hierarchies (E2), our simulation model captures about $42 \%(=100 \cdot 2.7 / 6.4)$ of the gender wage 


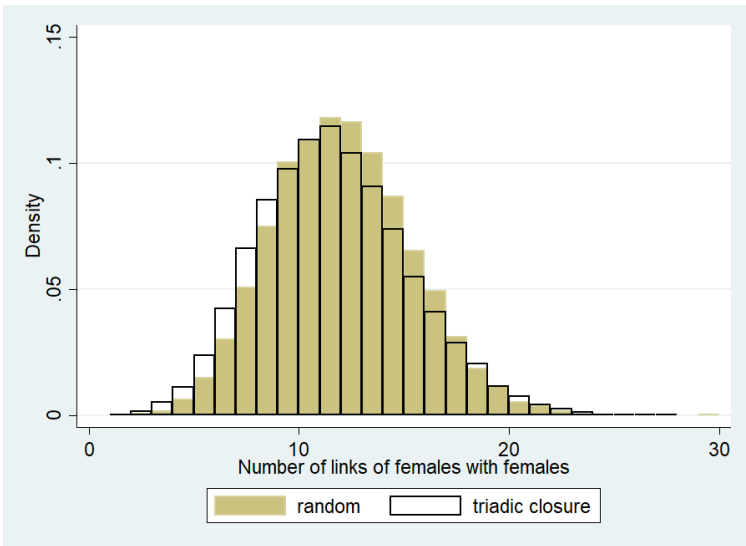

(a) Mean $=11.6 ;$ Variance $=11.0$

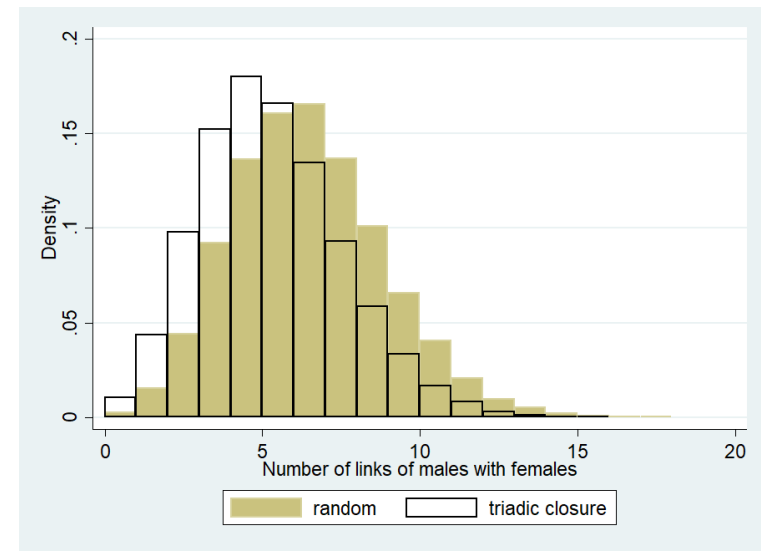

(c) Mean $=5.9 ;$ Variance $=5.9$

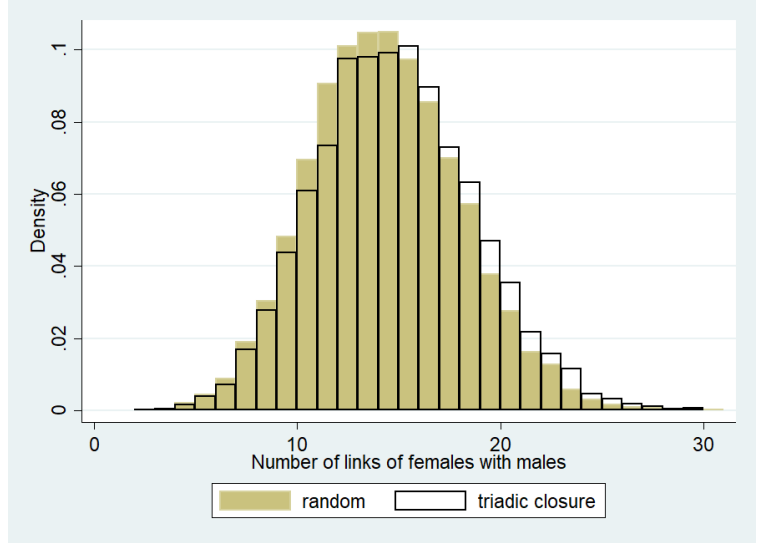

(b) Mean $=13.9 ;$ Variance $=13.7$

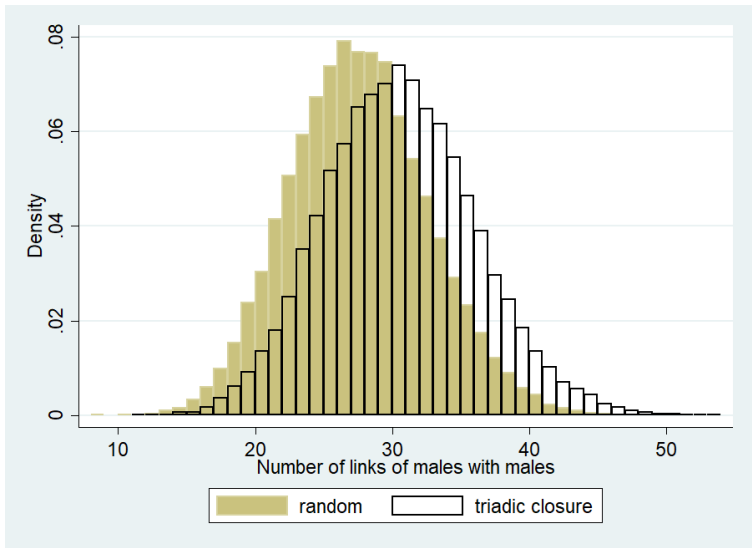

(d) Mean $=27.1 ;$ Variance $=25.8$

Figure 7: Distribution of network links

Notes: Histograms show directed links per worker by gender for models E1 (4 hierarchial levels with random network - grey bars) and E2 (4 hierarchical levels with triadic closure - black lines). Distributions are based on workers network links at the 1000th iteration for 50 runs. Means and variances are stated for the distributions of model E1. We calculated the global clustering coefficients which is defined as the number of closed triplets over the number of all triplets (both open and closed). The global clustering coefficient increases from 0.032 to 0.041 when going from model E1 to model E2. 
differential that arises empirically due to a relatively larger representation of women on lower managerial levels.

\section{Conclusions}

In this paper we were interested in the extent to which the gender wage gap can be explained by high-skilled female workers not making it to the higher managerial positions in firms. We addressed the question by, first, setting up and analyzing an analytical model that, later on, was accompanied by an agent-based simulation model to take into account further explanatory factors. Our model extends the existing literature on search and matching models, networks, and discrimination by adding more structure than can usually be found to the operation of the firm. In particular, we model various hierarchical levels, accumulation of human capital on the job, and referrer behavior in firms jointly. By doing so, a set of new and interesting results could be obtained. We show that an unequal representation of women along the managerial positions of firms may emerge without discrimination. Two requirements have to be fulfilled for this to occur: women need to be under-represented in the labor market and network formation has to be homophilous. If these two requirements are fulfilled, the disproportional representation of women on top managerial positions becomes, moreover, stronger as firms have more hierarchy levels, networks are more clustered (e.g. by triadic closures), and discrimination takes place for promotions within firms.

Thus, part of the gender pay gap is reflected in women being under-represented in better paying managerial jobs, and there are reasons why women do not make it to the top positions which are not necessarily related to discrimination or occupational segregation. In fact, it may suffice that labor market participation of women is lower than for men -which is the case in many occupations (ILO, 2017) - and that workers are more inclined to form propfessional network links with others of the same gender. Whether both requirements fulfilled could already be the result of discrimination needs discussion. If, for example, lower female labor force participation is the result of young women not investing into human capital because they are systematically kept out of higher education in general or certain fields, as it is often observed in engineering studies or the natural sciences, then discrimination would already have taken place before our analysis starts. Similarly, one could rightly argue that the formation of networks along the gender-dimension is already the result of discrimination. Men might want to form a network link with another men rather than a women because they want to keep women out of their relevant labor market. We would speak of discrimination here in the sense of Borjas (2013, p.367) who defines it as something that "... occurs when participants in the marketplace take into account such factors as race and sex when making economic exchanges." Such a reasoning, however, would disregard all other factors why men like to hook up more with men, and women more with women which are orthogonal to getting a referral sometimes in the future.

In empirical terms our analysis suggests that as we observe flatter firm hierarchies in the future (Rajan and Wulf, 2006; Guadalupe and Wulf, 2010) also the gender wage differential should decline. Moreover, our analysis bears some interesting policy implications. As homophilous networks are one driver behind the dis-proportionate gender distribution of managerial jobs, it occurs to be advisable to establish instruments that are conducive to gender-mixing of net- 
works. Policies that encourage women's only networks at workplaces, as can be often observed nowadays, seem to be the wrong way to go. Our analysis also suggests that policies which successfully raise female labor force participation to the levels of male workers will also erase wage differentials even if network formation remains homophilous.

\section{Acknowledgements}

We would like to thank the members of the ZIF Research Group "In Search of the Global Labour Market: Actors, Structures and Policies" for the continuing support and contributions, in particular at our Workshop on "Social Networks, Referrals and Neighborhood Effects in Frictional Labour Markets". The paper also benefited from colleagues' comments at the Workshop on Applied Economics at Philips-Universität Marburg and the research seminar at DICE, Düsseldorf.

\section{References}

Addison, J. T. and P. Portugal (2002). Job search methods and outcomes. Oxford Economic Papers 54(3), 505-533.

Arbex, M., D. O'Dea, and D. Wiczer (2018). Network search: Climbing the job ladder faster. Stony Brook University, Working Paper 2018-04.

Barabâsi, A.-L., H. Jeong, Z. Néda, E. Ravasz, A. Schubert, and T. Vicsek (2002). Evolution of the social network of scientific collaborations. Physica A: Statistical mechanics and its applications 311(3-4), 590-614.

Bentolila, S., C. Michelacci, and J. Suarez (2010). Social contacts and occupational choice. Economica 77(305), 20-45.

Bergmann, B. R. (1990). Micro-to-macro simulation: A primer with a labor market example. Journal of Economic Perspectives 4(1), 99-116.

Bertrand, M., B. S. E., S. Jensen, and A. Lleras-Muney (2018). Breaking the glass-ceiling? The effect of board quatas on female labor market outcomes in Norway. The Review of Economic Studies, forthcoming.

Blau, F. D. and J. DeVaro (2007). New evidence on gender differences in promotion rates: An empirical analysis of a sample of new hires. Industrial Relations: a Journal of Economy and Society 46(3), 511-550.

Blau, F. D. and L. M. Kahn (2017). The gender wage gap: Extent, trends and explanations. Journal of Economic Literature 55(3), 789-865.

Bloom, N., R. Sadun, and J. V. Reenen (2010). Recent advances in the empirics of organizational economics. Annual Review of Economics 2(1), 105-137.

Booth, A. L., M. Francesconi, and J. Frank (2018). A sticky floors model of promotion, pay and gender. European Economic Review 47, 295-322. 
Borjas, G. J. (2013). Labor economics (Sixth Edition, International ed.). New York: McGraw Hill.

Bramoullé, Y. and G. Saint-Paul (2010). Social networks and labor market transitions. Labour Economics 17(1), 188-195.

Caliendo, L., F. Monte, and E. Rossi-Hansberg (2015). The anatomy of French production hierarchies. Journal of Political Economy 123(4), 809-852.

Calvó-Armengol, A. (2004). Job contact networks. Journal of Economic Theory 115, 191-206.

Calvó-Armengol, A. and M. O. Jackson (2004). The effects of social networks on employment and inequality. American Economic Review 94 (3), 426-454.

Calvó-Armengol, A. and Y. Zenou (2005). Job matching, social network and word-of-mouth communication. Journal of Urban Economics 57(3), 500-522.

Cassidy, H., J. DeVaro, and A. Kauhanen (2016). Promotion signaling, gender, and turnover: New theory and evidence. Journal of Economic Behavior \& Organization 126, 140-166.

Chadi, A. and L. Goerke (2018). Missing at work - sickness-related absence and subsequent career events. Journal of Economic Behavior \& Organization 153, 153-176.

Cingano, F. and A. Rosolia (2012). People I know: Job search and social networks. Journal of Labor Economics 30(2), 291-332.

Cobb-Clark, D. A. (2001). Getting ahead: the determinants of and payoffs to internal promotion for young us men and women. Worker wellbeing in a changing labor market 20, 339-372.

Davis, G. F., M. Yoo, and W. E. Baker (2003). The small world of the American corporate elite, 1982-2001. Strategic Organization 1(3), 301-326.

Dawid, H. and S. Gemkow (2013). How do social networks contribute to wage inequality? Insights from an agent-based analysis. Industrial and Corporate Change 23(5), 1171-1200.

Dawid, H., M. Mitkova, and A. Zaharieva (2018). Professional careers, promotions and organizational hierarchies in a frictional labour market. Bielefeld University, Working Paper.

Diamond, P. A. (1982). Wage determination and efficiency in search equilibrium. The Review of Economic Studies 49(2), 217-227.

Fernandez, R. M. and M. Abraham (2010). From metaphors to mechanisms: Gender sorting in(to) an organizational hierarchy. MIT Sloan School Working Paper 4779-10.

Fernandez, R. M. and M. Abraham (2011). Glass ceilings and glass doors? Internal and external hiring in an organizational hierarchy. MIT Sloan School Working Paper 4895-11.

Fernandez, R. M. and S. Campero (2017). Gender sorting and the glass ceiling in high-tech firms. ILR Review 70(1), 73-104.

Fernandez, R. M. and L. M. Sosa (2005). Gendering the job: Networks and recruitment at a call center. American Journal of Sociology 111(3), 859-904. 
Fernandez-Mateo, I. and R. M. Fernandez (2016). Bending the pipeline? Executive search and gender inequality in hiring for top management jobs. Management Science 62 (12), 3636-3655.

Firth, M. (1982). Sex discrimination in job opportunities for women. Sex Roles 8(8), 891-901.

Fontaine, F. (2008). Why are similar workers paid differently? The role of social networks. Journal of Economic Dynamics and Control 32(12), 3960-3977.

Francois, P. (1998). Gender discrimination without gender difference: theory and policy responses. Journal of Public Economics 68, 1-32.

Freeman, R. B. (1998). War of the models: Which labour market institutions for the 21st century? Labour Economics 5(1), 124.

Galenianos, M. (2013). Learning about match quality and the use of referrals. Review of Economic Dynamics 16(4), 668-690.

Galenianos, M. (2014). Hiring through referrals. Journal of Economic Theory 152, 304-323.

Gemkow, S. and M. Neugart (2011). Referral hiring, endogenous social networks, and inequality: An agent-based analysis. Journal of Evolutionary Economics 21(4), 703-719.

Gibbons, R. and M. Waldman (1999). A theory of wage and promotion dynamics inside firms. The Quarterly Journal of Economics 114(4), 1321-1358.

Glitz, A. (2017). Coworker networks in the labour market. Labour Economics 44, 218-230.

Guadalupe, M. and J. Wulf (2010). The flattening firm and product market competition: The effect of trade liberalization on corporate hierarchies. American Economic Journal: Applied Economics 2(4), 105-27.

Holme, P., C. R. Edling, and F. Liljeros (2004). Structure and time evolution of an internet dating community. Social Networks 26(2), 155-174.

Horvath, G. (2014). On-the-job search and finding a good job through social contacts. The B.E. Journal of Theoretical Economics 14(1), 93-125.

ILO (2016). Global wage report 2016/17: Wage inequality in the workplace. Geneva: International Labour Office.

ILO (2017). World employment social outlook: trends for women 201\%. Geneva: International Labour Office.

Ingram, P. and P. W. Roberts (2000). Friendships among competitors in the Sydney hotel industry. American Journal of Sociology 106(2), 387-423.

Ioannides, Y. M. and A. Soetevent (2006). Wages and employment in a random social network with arbitrary degree distribution. The American Economic Review 96(2), 270-274.

Kauhanen, A. and S. Napari (2015). Gender differences in careers. Annals of Economics and Statistics 117-118, 61-88. 
Kmec, J. A. (2005). Setting occupational sex segregation in motion: Demand-side explanations of sex traditional employment. Work and Occupations 32(3), 322-354.

König, M. D., C. J. Tessone, and Y. Zenou (2014). Nestedness in networks: A theoretical model and some applications. Theoretical Economics 9(3), 695-752.

Lluis, S. (2005). The role of comparative advantage and learning in wage dynamics and intrafirm mobility: Evidence from Germany. Journal of Labor Economics 23(4), 725-767.

McKinsey\&Company (2017). Women in the workplace. McKinsey\&Company.

McPherson, M., L. Smith-Lovin, and J. M. Cook (2001). Birds of a feather: Homophily in social networks. Annals Review of Sociology 27, 415-444.

Milgrom, P. and S. Oster (1987). Job discrimination, market forces, and the invisibility hypothesis. The Quarterly Journal of Economics 102(3), 453-476.

Montgomery, J. D. (1991). Social networks and labor-market outcomes: Toward an economic analysis. The American Economic Review 81(5), 1408-1418.

Mortensen, D. T. (1982). The matching process as a noncooperative bargaining game. In J. McCall (Ed.), The Economics of Information and Uncertainty, pp. 233-258. University of Chicago Press.

Mortensen, D. T. and T. Vishwanath (1994). Personal contacts and earnings: It is who you know! Labour Economics 1, 187-201.

Neugart, M. and M. Richiardi (2018). Agent-based models of the labor market. In S.-H. Chen, M. Kaboudan, and Y.-R. Du (Eds.), The Oxford Handbook of Computational Economics and Finance, Chapter 22, pp. 667-687. Oxford: Oxford University Press.

Neumark, D., R. J. Bank, and K. D. Van Nort (1996). Sex discrimination in restaurant hiring: An audit study. The Quarterly Journal of Economics 111(3), 915-941.

Newman, M. E. and M. Girvan (2004). Finding and evaluating community structure in networks. Physical Review E 69(2), 026113.

Oaxaca, R. (1973). Male-female wage differentials in urban labor markets. International Economic Review 14, 693-709.

Opsahl, T. and P. Panzarasa (2009). Clustering in weighted networks. Social Networks 31(2), $155-163$.

Pellizzari, M. (2010). Do friends and relatives really help in getting a good job? Industrial and Labor Relations Review 63(3), 494-510.

Petit, P. (2007). The effects of age and family constraints ongender hiring discrimination: A field experiment in the French financial sector. Labor Economics 14, 371-391.

Petrongolo, B. and C. A. Pissarides (2001). Looking into the black box: A survey of the matching function. Journal of Economic literature 39(2), 390-431. 
Pissarides, C. A. (1985). Short-run equilibrium dynamics of unemployment, vacancies, and real wages. The American Economic Review 75(4), 676-690.

Pistaferri, L. (1999). Informal networks in the Italian labor market. Giornale degli Economisti e Annali di Economia 58(3-4), 355-375.

Rajan, R. G. and J. Wulf (2006). The flattening firm: Evidence from panel data on the changing nature of corporate hierarchies. The Review of Economics and Statistics 88(4), 759-773.

Rebien, M., M. Stops, and A. Zaharieva (2017). Formal search and referrals from a firm's perspective. IMW Working Paper 578.

Rubineau, B. and R. M. Fernandez (2013). Missing links: Referrer behavior and job segregation. Management Science 59(11), 2470-2489.

Rubineau, B. and R. M. Fernandez (2015). Tipping points: The gender segregating and desegregating effects of network recruitment. Organization Science 26 (6), 1646-1664.

Simmel, G. (1908). Untersuchungen über die Formen der Vergesellschaftung (7. Auflage 2013 ed.). Verlag Duncker \& Humblot Berlin.

SOEP (2013). German Socio-Economic Panel (SOEP), data of the years 1984-2013. doi:10.5684/soep.v30.

Stovel, K. and C. Fountain (2009). The social dynamics of matching processes. In P. Hedstrom and P. Bearman (Eds.), The Handbook of Analytical Sociology, Chapter 16, pp. 365-390. New York: Oxford University Press.

Stupnytska, Y. and A. Zaharieva (2017). Optimal policy and the role of social contacts in a search model with heterogeneous workers. Journal of Public Economic Theory 19(5), 957-985.

Tassier, T. and F. Menczer (2008). Social network structure, segregation, and equality in a labor market with referral hiring. Journal of Economic Behavior 83 Organization 66 (3-4), 514-528.

Uzzi, B. and J. Spiro (2005). Collaboration and creativity: The small world problem. American Journal of Sociology 111(2), 447-504.

Watts, D. J. and S. H. Strogatz (1998). Collective dynamics of 'small-world' networks. Nature 393, 440-442.

Zaharieva, A. (2015). Social contacts and referrals in a labor market with on-the-job search. Labour Economics 32, 27-43.

\section{Appendix}

\section{Appendix I: Blinder-Oaxaca decomposition}

In this subsection, we perform the Blinder-Oaxaca decomposition of wage differences between men and women in Germany. The data comes from the German Socio-Economic Panel, wave 
2013. We restrict our attention to full-time employed high skill men and women with more than 13 years of schooling. This sample includes 2403 observations with 1446 observations for men and 957 observations for women. The average monthly gross salary of men is equal to 8.36 in logarithmic terms, while the average salary of women is equal to 8.05 . This reveals a gender wage gap equal to $31 \%$. We decompose this difference by using a triple Blinder-Oaxaca decomposition according to the following equation:

$$
\begin{aligned}
\text { Wage gap } & =E\left[Y^{M}\right]-E\left[Y^{F}\right]=E\left[X^{M}\right]^{\prime} \beta^{M}-E\left[X^{F}\right]^{\prime} \beta^{F} \\
& =\underbrace{\left(E\left[X^{M}\right]^{\prime}-E\left[X^{F}\right]^{\prime}\right) \beta^{F}}_{\text {Endowment effect }}+\underbrace{E\left[X^{F}\right]^{\prime}\left(\beta^{M}-\beta^{F}\right)}_{\text {Coefficient effect }}+\underbrace{\left(E\left[X^{M}\right]^{\prime}-E\left[X^{F}\right]^{\prime}\right)\left(\beta^{M}-\beta^{F}\right)}_{\text {Interaction effect }}
\end{aligned}
$$

with $Y_{M}$ and $Y_{F}$ as male and female wages, respectively. $X$ is a vector of explanatory variables that includes information on education, age, tenure, migration background, industry, size of the firm, location with respect to East or West Germany, and hierarchical position in the firm. $\beta_{F}$ and $\beta_{M}$ are the vectors of estimated coefficients. The first term in the decomposition is the "Endowment effect". It shows which part of the wage gap can be explained by between-group differences in the observable characteristics. The second term is the "Coefficient effect". It shows which part of the wage gap can be explained by different pricing of female and male characteristics in the market. The last effect shows the interaction between the endowment and the coefficient effects. Our decomposition results are summarised in Table 6. We can see that $16.4 \%$ of the total wage gap equal to $31 \%$ is explained by differences in the observable characteristics of men and women. The second column of Table 7 shows the contribution of every explanatory variable $k$ to the total endowment effect $\left(E\left[X_{k}^{M}\right]-E\left[X_{k}^{F}\right]\right) \beta_{k}^{F}$. We can see that differences in the hierarchical levels between the two gender groups explain $6.4 \%$ out of the endowment effect equal to $16.4 \%$. We interpret this $6.4 \%$ difference as the glass-ceiling effect.

Table 6: Summary of Blinder-Oaxaca decomposition

\begin{tabular}{c||c|c|c}
\hline Gender wage gap & Endowments & Coefficients & Interaction \\
\hline $0.3078^{* * *}$ & $0.1642^{* * *}$ & $0.1741^{* * *}$ & $-0.0306^{*}$ \\
\hline
\end{tabular}


Table 7: Regression results of Blinder-Oaxaca decomposition

\begin{tabular}{|c|c|c|c|c|}
\hline $\bar{N}=2403$ & $\begin{array}{c}(1) \\
\text { LNincome }\end{array}$ & $\begin{array}{c}(2) \\
\text { Endowments }\end{array}$ & $\begin{array}{c}(3) \\
\text { Coefficients }\end{array}$ & $\begin{array}{c}(4) \\
\text { Interaction }\end{array}$ \\
\hline Male & $\begin{array}{c}0.154^{* * * *} \\
(8.76)\end{array}$ & & & \\
\hline Level & $\begin{array}{c}0.196^{* * *} \\
(18.17)\end{array}$ & $\begin{array}{c}-0.0639^{* * *} \\
(-8.07)\end{array}$ & $\begin{array}{c}-0.0700 \\
(-1.68)\end{array}$ & $\begin{array}{l}0.0117 \\
(1.65)\end{array}$ \\
\hline Education & $\begin{array}{c}0.0746^{* * *} \\
(16.61)\end{array}$ & $\begin{array}{c}-0.00711 \\
(-1.24)\end{array}$ & $\begin{array}{l}0.104 \\
(0.71)\end{array}$ & $\begin{array}{c}-0.000646 \\
(-0.61)\end{array}$ \\
\hline Age & $\begin{array}{c}0.0634^{* * *} \\
(10.90)\end{array}$ & $\begin{array}{c}-0.187^{* * *} \\
(-4.69)\end{array}$ & $\begin{array}{l}-1.058 \\
(-1.84)\end{array}$ & $\begin{array}{l}0.0581 \\
(1.74)\end{array}$ \\
\hline$A g e^{2}$ & $\begin{array}{c}-0.000605^{* * *} \\
(-9.31)\end{array}$ & $\begin{array}{c}0.149^{* * *} \\
(4.38)\end{array}$ & $\begin{array}{l}0.440 \\
(1.39)\end{array}$ & $\begin{array}{c}-0.0420 \\
(-1.34)\end{array}$ \\
\hline Tenure & $\begin{array}{c}0.00518^{* * *} \\
(4.84)\end{array}$ & $\begin{array}{c}-0.00374 \\
(-1.76)\end{array}$ & $\begin{array}{c}0.0596^{*} \\
(2.05)\end{array}$ & $\begin{array}{c}-0.00522 \\
(-1.62)\end{array}$ \\
\hline Native & $\begin{array}{c}0.0813 \\
(1.58)\end{array}$ & $\begin{array}{c}0.000278 \\
(0.45)\end{array}$ & $\begin{array}{l}0.183 \\
(1.69)\end{array}$ & $\begin{array}{c}0.00180 \\
(1.11)\end{array}$ \\
\hline Agriculture & - & $\begin{array}{c}0.00224 \\
(1.77)\end{array}$ & $\begin{array}{c}-0.000297 \\
(-0.11)\end{array}$ & $\begin{array}{c}0.000175 \\
(0.11)\end{array}$ \\
\hline Energy & $\begin{array}{c}0.307^{* *} \\
(2.90)\end{array}$ & $\begin{array}{c}-0.0000435 \\
(-0.06)\end{array}$ & $\begin{array}{c}0.00269 \\
(0.96)\end{array}$ & $\begin{array}{c}-0.00150 \\
(-0.89)\end{array}$ \\
\hline Mining & $\begin{array}{c}0.831^{* * * *} \\
(3.85)\end{array}$ & $\begin{array}{c}-0.000620 \\
(-0.63)\end{array}$ & $\begin{array}{c}-0.000190 \\
(-0.22)\end{array}$ & $\begin{array}{c}0.0000945 \\
(0.21)\end{array}$ \\
\hline Manufacturing & $\begin{array}{c}0.250^{* *} \\
(3.13)\end{array}$ & $\begin{array}{c}0.000715 \\
(0.30)\end{array}$ & $\begin{array}{c}0.00219 \\
(0.18)\end{array}$ & $\begin{array}{c}-0.000845 \\
(-0.18)\end{array}$ \\
\hline Construction & $\begin{array}{c}0.325^{* * *} \\
(4.02)\end{array}$ & $\begin{array}{c}-0.00605 \\
(-1.64)\end{array}$ & $\begin{array}{c}-0.00459 \\
(-0.39)\end{array}$ & $\begin{array}{c}0.00299 \\
(0.39)\end{array}$ \\
\hline Trade & $\begin{array}{c}-0.0573 \\
(-0.69)\end{array}$ & $\begin{array}{c}-0.00308 \\
(-0.98)\end{array}$ & $\begin{array}{c}-0.00189 \\
(-0.37)\end{array}$ & $\begin{array}{c}-0.000327 \\
(-0.35)\end{array}$ \\
\hline Transportation & $\begin{array}{l}0.192^{*} \\
(2.20)\end{array}$ & $\begin{array}{c}0.000593 \\
(0.83)\end{array}$ & $\begin{array}{c}-0.00104 \\
(-0.25)\end{array}$ & $\begin{array}{c}0.000229 \\
(0.24)\end{array}$ \\
\hline Banking & $\begin{array}{c}0.300^{* * *} \\
(3.56)\end{array}$ & $\begin{array}{c}-0.000737 \\
(-0.66)\end{array}$ & $\begin{array}{c}0.00141 \\
(0.23)\end{array}$ & $\begin{array}{c}-0.000474 \\
(-0.23)\end{array}$ \\
\hline Services & $\begin{array}{l}0.179^{*} \\
(2.32)\end{array}$ & $\begin{array}{c}-0.0150^{*} \\
(-2.25)\end{array}$ & $\begin{array}{c}0.00189 \\
(0.06)\end{array}$ & $\begin{array}{c}0.000738 \\
(0.06)\end{array}$ \\
\hline Firmsize $\leq 5$ & - & $\begin{array}{c}-0.000602 \\
(-0.34)\end{array}$ & $\begin{array}{c}0.00144 \\
(0.36)\end{array}$ & $\begin{array}{c}0.0000767 \\
(0.25)\end{array}$ \\
\hline $5<$ Firmsize $\leq 10$ & $\begin{array}{c}0.167^{* * *} \\
(3.63)\end{array}$ & $\begin{array}{c}0.000670 \\
(0.90)\end{array}$ & $\begin{array}{c}-0.00551 \\
(-1.66)\end{array}$ & $\begin{array}{c}-0.00128 \\
(-1.00)\end{array}$ \\
\hline $10<$ Firmsize $\leq 20$ & $\begin{array}{c}0.160 * * * \\
(3.53)\end{array}$ & $\begin{array}{c}-0.000604 \\
(-0.39)\end{array}$ & $\begin{array}{c}0.00128 \\
(0.45)\end{array}$ & $\begin{array}{c}0.000958 \\
(0.44)\end{array}$ \\
\hline $20<$ Firmsize $\leq 100$ & $\begin{array}{c}0.136^{* * *} \\
(3.65)\end{array}$ & $\begin{array}{c}-0.000705 \\
(-0.91)\end{array}$ & $\begin{array}{c}-0.000136 \\
(-0.02)\end{array}$ & $\begin{array}{c}-0.0000197 \\
(-0.02)\end{array}$ \\
\hline $100<$ Firmsize $\leq 200$ & $\begin{array}{c}0.192^{* * *} \\
(4.58)\end{array}$ & $\begin{array}{c}0.0000718 \\
(0.30)\end{array}$ & $\begin{array}{c}0.00330 \\
(0.73)\end{array}$ & $\begin{array}{c}0.000182 \\
(0.35)\end{array}$ \\
\hline $200<$ Firmsize $\leq 2000$ & $\begin{array}{c}0.191^{* * *} \\
(5.29)\end{array}$ & $\begin{array}{c}-0.000289 \\
(-0.59)\end{array}$ & $\begin{array}{c}0.00466 \\
(0.54)\end{array}$ & $\begin{array}{c}-0.000269 \\
(-0.45)\end{array}$ \\
\hline $2000<$ Firmsize & $\begin{array}{c}0.280 * * * \\
(7.88)\end{array}$ & $\begin{array}{c}-0.00813^{* *} \\
(-2.99)\end{array}$ & $\begin{array}{c}0.000196 \\
(0.02)\end{array}$ & $\begin{array}{c}-0.0000384 \\
\quad(-0.02)\end{array}$ \\
\hline West & $\begin{array}{c}0.231^{* * *} \\
(11.73)\end{array}$ & $\begin{array}{c}-0.0200^{* * *} \\
(-3.82)\end{array}$ & $\begin{array}{c}-0.0652^{*} \\
(-2.06)\end{array}$ & $\begin{array}{c}0.00616 \\
(1.84)\end{array}$ \\
\hline Constant & $\begin{array}{c}4.362^{* * *} \\
(26.41)\end{array}$ & & & \\
\hline Adj. $R^{2}$ & 0.4662 & & & \\
\hline
\end{tabular}

Data source: SOEP (2013). Sample is restricted to high-skill full-time employees. $t$ statistics in parentheses, * $p<0.05,{ }^{* *} p<0.01,{ }^{* * *} p<0.001$. 


\section{Appendix II: Solution to differential equations}

We consider the system of differential equations for female workers $\dot{d}_{F 0}, \dot{d}_{F F}^{N}$ and $\dot{d}_{F M}^{N}$, first. The coefficient matrix and the characteristic equation for $r$ are given by:

$$
\begin{gathered}
\left(\begin{array}{ccc}
-\left(\rho+q_{2}\right) & \rho & \rho \\
q_{2}\left(1-\alpha_{2}\right) & -2 \rho & 0 \\
q_{2} \alpha_{2} & 0 & -2 \rho
\end{array}\right) \\
\left(-\rho-q_{2}-r\right)(-2 \rho-r)(-2 \rho-r)-\rho q_{2}\left(1-\alpha_{2}\right)(-2 \rho-r)-\rho q_{2} \alpha_{2}(-2 \rho-r)=0
\end{gathered}
$$

The first eigenvalue is given by $r_{1}=-2 \rho$. The remaining quadratic term is:

$$
r^{2}+r\left(q_{2}+3 \rho\right)+2 \rho^{2}+2 \rho q_{2}-\rho q_{2}=0
$$

The discriminant of this quadratic equation is $\left(q_{2}+\rho\right)^{2}$, so the second and the third eigenvalues are given by $r_{2}=-\rho, r_{3}=-\left(q_{2}+2 \rho\right)$. The corresponding three eigenvectors are given by:

$$
\left(\begin{array}{c}
0 \\
1 \\
-1
\end{array}\right) \quad\left(\begin{array}{c}
\frac{\rho^{2}}{q_{2}} \\
\rho\left(1-\alpha_{2}\right) \\
\rho \alpha_{2}
\end{array}\right) \quad\left(\begin{array}{c}
-q_{2} \\
q_{2}\left(1-\alpha_{2}\right) \\
q_{2} \alpha_{2}
\end{array}\right)
$$

The general solution is given by:

$$
\begin{aligned}
d_{F 0}(x) & =k_{2}^{F} \frac{\rho^{2}}{q_{2}} e^{-\rho x}-k_{3}^{F} q_{2} e^{-\left(2 \rho+q_{2}\right) x} \\
d_{F F}^{N}(x) & =k_{1}^{F} e^{-2 \rho x}+k_{2}^{F} \rho\left(1-\alpha_{2}\right) e^{-\rho x}+k_{3}^{F} q_{2}\left(1-\alpha_{2}\right) e^{-\left(2 \rho+q_{2}\right) x} \\
d_{F M}^{N}(x) & =-k_{1}^{F} e^{-2 \rho x}+k_{2}^{F} \rho \alpha_{2} e^{-\rho x}+k_{3}^{F} q_{2} \alpha_{2} e^{-\left(2 \rho+q_{2}\right) x}
\end{aligned}
$$

The three constant terms $k_{1}^{F}, k_{2}^{F}$ and $k_{3}^{F}$ can be found from the following initial conditions: $q_{1}\left(1-\alpha_{1}\right) d_{00}=d_{F 0}(0), \bar{q}_{1}^{F F} d_{0 F}=d_{F F}^{N}(0)$ and $\bar{q}_{1}^{F M} d_{0 M}=d_{F M}^{N}(0)$ :

$$
\begin{aligned}
d_{F 0}(0) & =k_{2}^{F} \frac{\rho^{2}}{q_{2}}-k_{3}^{F} q_{2}=q_{1}\left(1-\alpha_{1}\right) d_{00} \\
d_{F F}^{N}(0) & =k_{1}^{F}+k_{2}^{F} \rho\left(1-\alpha_{2}\right)+k_{3}^{F} q_{2}\left(1-\alpha_{2}\right)=\bar{q}_{1}^{F F} d_{0 F} \\
d_{F M}^{N}(0) & =-k_{1}^{F}+k_{2}^{F} \rho \alpha_{2}+k_{3}^{F} q_{2} \alpha_{2}=\bar{q}_{1}^{F M} d_{0 M}
\end{aligned}
$$

Adding the latter two equations we can express $k_{3}^{F} q_{2}=\bar{q}_{1}^{F F} d_{0 F}+\bar{q}_{1}^{F M} d_{0 M}-k_{2}^{F} \rho$. Then inserting it into the first equation we get:

$$
\begin{aligned}
k_{2}^{F} & =\frac{q_{2}}{\rho\left(\rho+q_{2}\right)}\left[q_{1}\left(1-\alpha_{1}\right) d_{00}+\bar{q}_{1}^{F F} d_{0 F}+\bar{q}_{1}^{F M} d_{0 M}\right] \\
k_{3}^{F} & =\frac{\rho}{q_{2}\left(\rho+q_{2}\right)}\left[\bar{q}_{1}^{F F} d_{0 F}+\bar{q}_{1}^{F M} d_{0 M}\right]-\frac{q_{1}\left(1-\alpha_{1}\right)}{\rho+q_{2}} d_{00} \\
k_{1}^{F} & =\alpha_{2} \bar{q}_{1}^{F F} d_{0 F}-\left(1-\alpha_{2}\right) \bar{q}_{1}^{F M} d_{0 M}
\end{aligned}
$$


Integrating $d_{F 0}(x)$ over $x$ in the interval $[0 . . \bar{x}]$ we get the total stock of firms $d_{F 0}$ :

$$
d_{F 0}=\int_{0}^{\bar{x}}\left[k_{2}^{F} \frac{\rho^{2}}{q_{2}} e^{-\rho x}-k_{3}^{F} q_{2} e^{-\left(2 \rho+q_{2}\right) x}\right] d x=\frac{k_{2}^{F} \rho}{q_{2}}\left(1-e^{-\rho \bar{x}}\right)-\frac{k_{3}^{F} q_{2}}{2 \rho+q_{2}}\left(1-e^{-\left(2 \rho+q_{2}\right) \bar{x}}\right)
$$

Integrating $d_{F F}^{N}(x)$ over $x$ in the interval $[0 . . \bar{x}]$ we get the total stock of firms $d_{F F}^{N}$ :

$$
\begin{aligned}
d_{F F}^{N} & =\int_{0}^{\bar{x}}\left[k_{1}^{F} e^{-2 \rho x}+k_{2}^{F} \rho\left(1-\alpha_{2}\right) e^{-\rho x}+k_{3}^{F} q_{2}\left(1-\alpha_{2}\right) e^{-\left(2 \rho+q_{2}\right) x}\right] d x \\
& =\frac{k_{1}^{F}}{2 \rho}\left(1-e^{-2 \rho \bar{x}}\right)+k_{2}^{F}\left(1-\alpha_{2}\right)\left(1-e^{-\rho \bar{x}}\right)+\frac{k_{3}^{F} q_{2}\left(1-\alpha_{2}\right)}{2 \rho+q_{2}}\left(1-e^{-\left(2 \rho+q_{2}\right) \bar{x}}\right)
\end{aligned}
$$

Integrating $d_{F M}^{N}(x)$ over $x$ in the interval $[0 . . \bar{x}]$ we get the total stock of firms $d_{F M}^{N}$ :

$$
\begin{aligned}
d_{F M}^{N} & =\int_{0}^{\bar{x}}\left[-k_{1}^{F} e^{-2 \rho x}+k_{2}^{F} \rho \alpha_{2} e^{-\rho x}+k_{3}^{F} q_{2} \alpha_{2} e^{-\left(2 \rho+q_{2}\right) x}\right] d x \\
& =-\frac{k_{1}^{F}}{2 \rho}\left(1-e^{-2 \rho \bar{x}}\right)+k_{2}^{F} \alpha_{2}\left(1-e^{-\rho \bar{x}}\right)+\frac{k_{3}^{F} q_{2} \alpha_{2}}{2 \rho+q_{2}}\left(1-e^{-\left(2 \rho+q_{2}\right) \bar{x}}\right)
\end{aligned}
$$

Next we consider the system of differential equations for male workers $\dot{d}_{M 0}, \dot{d}_{M M}^{N}$ and $\dot{d}_{M F}^{N}$. The coefficient matrix is given by:

$$
\left(\begin{array}{ccc}
-\left(\rho+q_{2}\right) & \rho & \rho \\
q_{2} \alpha_{2} & -2 \rho & 0 \\
q_{2}\left(1-\alpha_{2}\right) & 0 & -2 \rho
\end{array}\right)
$$

The eigenvalues are the same, but the eigenvectors are slightly different and given by:

$$
\left(\begin{array}{c}
0 \\
1 \\
-1
\end{array}\right) \quad\left(\begin{array}{c}
\frac{\rho^{2}}{q_{2}} \\
\rho \alpha_{2} \\
\rho\left(1-\alpha_{2}\right)
\end{array}\right) \quad\left(\begin{array}{c}
-q_{2} \\
q_{2} \alpha_{2} \\
q_{2}\left(1-\alpha_{2}\right)
\end{array}\right)
$$

So the general solution becomes:

$$
\begin{aligned}
d_{M 0}(x) & =k_{2}^{M} \frac{\rho^{2}}{q_{2}} e^{-\rho x}-k_{3}^{M} q_{2} e^{-\left(2 \rho+q_{2}\right) x} \\
d_{M M}^{N}(x) & =k_{1}^{M} e^{-2 \rho x}+k_{2}^{M} \rho \alpha_{2} e^{-\rho x}+k_{3}^{M} q_{2} \alpha_{2} e^{-\left(2 \rho+q_{2}\right) x} \\
d_{M F}^{N}(x) & =-k_{1}^{M} e^{-2 \rho x}+k_{2}^{M} \rho\left(1-\alpha_{2}\right) e^{-\rho x}+k_{3}^{M} q_{2}\left(1-\alpha_{2}\right) e^{-\left(2 \rho+q_{2}\right) x}
\end{aligned}
$$

The initial conditions are: $q_{1} \alpha_{1} d_{00}=d_{M 0}(0), \bar{q}_{1}^{M M} d_{0 M}=d_{M M}^{N}(0)$ and $\bar{q}_{1}^{M F} d_{0 F}=d_{M F}^{N}(0)$. So we find the three constant terms $k_{1}^{M}, k_{2}^{M}$ and $k_{3}^{M}$ from the following system of equations:

$$
\begin{aligned}
d_{M 0}(0) & =k_{2}^{M} \frac{\rho^{2}}{q_{2}}-k_{3}^{M} q_{2}=q_{1} \alpha_{1} d_{00} \\
d_{M M}^{N}(0) & =k_{1}^{M}+k_{2}^{M} \rho \alpha_{2}+k_{3}^{M} q_{2} \alpha_{2}=\bar{q}_{1}^{M M} d_{0 M} \\
d_{M F}^{N}(0) & =-k_{1}^{M}+k_{2}^{M} \rho\left(1-\alpha_{2}\right)+k_{3}^{M} q_{2}\left(1-\alpha_{2}\right)=\bar{q}_{1}^{M F} d_{0 F}
\end{aligned}
$$


Adding the latter two equations we can express $k_{3}^{M} q_{2}=\bar{q}_{1}^{M M} d_{0 M}+\bar{q}_{1}^{M F} d_{0 F}-k_{2}^{M} \rho$. Then inserting it into the first equation we get:

$$
\begin{aligned}
k_{2}^{M} & =\frac{q_{2}}{\rho\left(\rho+q_{2}\right)}\left[q_{1} \alpha_{1} d_{00}+\bar{q}_{1}^{M M} d_{0 M}+\bar{q}_{1}^{M F} d_{0 F}\right] \\
k_{3}^{M} & =\frac{\rho}{q_{2}\left(\rho+q_{2}\right)}\left[\bar{q}_{1}^{M M} d_{0 M}+\bar{q}_{1}^{M F} d_{0 F}\right]-\frac{q_{1} \alpha_{1}}{\rho+q_{2}} d_{00} \\
k_{1}^{M} & =\left(1-\alpha_{2}\right) \bar{q}_{1}^{M M} d_{0 M}-\alpha_{2} \bar{q}_{1}^{M F} d_{0 F}
\end{aligned}
$$

